\title{
Probiotic Propionibacterium freudenreichii requires SIpB protein to mitigate mucositis induced by chemotherapy
}

Fillipe Luiz Rosa do Carmo ${ }^{1,2}$, Houem Rabah ${ }^{2,3}$, Barbara Fernandes Cordeiro ${ }^{1}$ Sara Heloisa da Silva', Rafaela Miranda Pessoa ${ }^{4}$, Simone Odília Antunes Fernandes ${ }^{4}$, Valbert Nascimento Cardoso ${ }^{4}$, Valérie Gagnaire ${ }^{2}$, Martine Deplanche ${ }^{2}$, Bruna Savassi ${ }^{1}$, Alessandra Figueiroa', Emiliano Rosa Oliveira', Caio César Fonseca', Maria Izabel Alves Queiroz, Núbia Morais Rodrigues', Sávio Henrique de Cicco Sandes', Álvaro Cantini Nunes', Luisa Lemos', Juliana de Lima Alves', Ana Maria Caetano Faria', Ênio Ferreira', Yves Le Loir ${ }^{2}$, Gwénaël Jan, ${ }^{2, *}$ and Vasco Azevedo, ${ }^{1, *}$

\footnotetext{
${ }^{1}$ Instituto de Ciências Biológicas, Universidade Federal de Minas Gerais (UFMG), Belo Horizonte, Minas Gerais, Brasil

${ }^{2}$ STLO, INRA, Agrocampus Ouest, UMR1253, Science \& Technologie du Lait \& de I'Oeuf, Rennes, France

${ }^{3} \mathrm{Bba}$, Pôle Agronomique Ouest, Régions Bretagne et Pays de la Loire, Rennes, France

${ }^{4}$ Department of Clinical and Toxicological Analysis, Federal University of Minas Gerais (UFMG), Belo Horizonte, Minas Gerais, Brazil

*These authors share senior authorship

Correspondence to: Gwénaël Jan, email: gwenael.jan@inra.fr

Keywords: mucositis; probiotic; surface protein; immunomodulation; inflammation

Received: June 11,2019 Accepted: October 21, 2019 Published: December 31, 2019

Copyright: do Carmo et al. This is an open-access article distributed under the terms of the Creative Commons Attribution License 3.0 (CC BY 3.0), which permits unrestricted use, distribution, and reproduction in any medium, provided the original author and source are credited.
}

\section{ABSTRACT}

Propionibacterium freudenreichii CIRM-BIA 129 (P. freudenreichii wild type, WT) is a probiotic bacterium, which exerts immunomodulatory effects. This strain possesses extractable surface proteins, including SIpB, which are involved in antiinflammatory effect and in adhesion to epithelial cells. We decided to investigate the impact of slpB gene mutation on immunomodulation in vitro and in vivo. In an in vitro assay, $P$. freudenreichii WT reduced expression of IL-8 $(p<0.0001)$ and TNF-a $(p<0.0001)$ cytokines in LPS-stimulated HT-29 cells. $P$. freudenreichii $\Delta s / p B$, lacking the SIpB protein, failed to do so. Subsequently, both strains were investigated in vivo in a 5-FU-induced mucositis mice model. Mucositis is a common side effect of cytotoxic chemotherapy with 5-FU, characterized by mucosal injury, inflammation, diarrhea, and weight loss. The WT strain prevented weight loss, reduced inflammation and consequently histopathological scores. Furthermore, it regulated key markers, including Claudin-1 (cld1, p<0.0005) and IL-17a $($ Il17a, $\mathrm{p}<0.0001)$ genes, as well as IL-12 $(p<0.0001)$ and IL-1 $\beta(p<0.0429)$ cytokines levels. Mutant strain displayed opposite regulatory effect on cld1 expression and on IL-12 levels. This work emphasizes the importance of SIpB in $P$. freudenreichii ability to reduce mucositis inflammation. It opens perspectives for the development of probiotic products to decrease side effects of chemotherapy using GRAS bacteria with immunomodulatory surface protein properties. 


\section{INTRODUCTION}

Propionibacterium freudenreichii represents the main species of dairy propionibacteria. It is a grampositive, non-motile, non-spore forming and anaerobic to aerotolerant beneficial bacterium, which plays an important role in food transformation, particularly in cheese ripening [1]. It has been listed in the Qualified Presumption of Safety list by the European food safety authority [2]. It was given the GRAS (Generally Recognized As Safe) status for its use in cheese [3]. Dairy propionibacteria are peculiar bacteria with a great probiotic potential. They produce the short chain fatty acids (SCFAs) acetate and propionate, and other beneficial metabolites, such as vitamin B9 and B12, as well as 1,4-dihydroxy-2-naphthoic acid (DHNA) and 2-amino3-carboxy-1,4-naphthoquinone (ACNQ), which were described as bifidogenic growth stimulators [1].

Probiotic effects of $P$. freudenreichii also include modulating the gut microbiota and the gut immune system [2]. In 2012, Cousin and collaborators demonstrated that dairy propionibacteria induce production of the regulatory cytokine IL-10 ex vivo in porcine colonic mucosa explants, and decrease production of proinflammatory cytokines, such as IL- 8 and tumor necrosis factor- $\alpha$ (TNF $\alpha)$, in the gut mucosa of piglets after lipopolysaccharides (LPS) stimulation [4].

P. freudenreichii strains, isolated or associated with other probiotic bacteria, have also been shown to attenuate colitis induced by trinitrobenzene sulfonic acid (TNBS), in BALB/c mice [5]. P. freudenreichii was also reported to reduce intestinal and systemic proinflammatory alterations, caused by a high-fat diet, in a mice model [6]. Moreover, dairy propionibacteria strains may alleviate symptoms and stabilize the intestinal microbiota in patients with irritable bowel syndrome [7]. Altogether, these studies attracted attention on $P$. freudenreichii as a promising probiotic to potentiate the treatment of inflammatory diseases [1].

$P$. freudenreichii strain ITGP20, equivalent to CIRM-BIA 129 (P. freudenreichii wild type, WT), was used for the development of two experimental cheeses, one single-strain, and one in association with Lactobacillus delbrueckii subsp lactis CNRZ327. Both cheeses gave promising results and alleviated TNBSinduced colitis in mice $[8,9]$. P. freudenreichii antiinflammatory effect was further shown to depend on specific extractable surface proteins [10]. A surface proteomic analysis of $P$. freudenreichii extractable surface proteins identified three surface-exposed ones, designated SlpA, SlpB and SlpE [10]. Interestingly, the extraction of surface proteins from $P$. freudenreichii WT by guanidine hydrochloride suppresses its ability to induce anti-inflammatory cytokines in human PBMCs [10]. Moreover, in P. freudenreichii WT, Carmo and collaborators confirmed that the surface protein SlpB is involved in adhesion to cultured human intestinal epithelial cells HT-29 [11], and mutation of the $\operatorname{slpB}$ gene caused drastic changes in surface properties [12]. In this context, the great probiotic potential of $P$. freudenreichii in the context of inflammatory bowel diseases $[8,9]$, and the presence of a characterized extractable surface protein SlpB with immunomodulatory activity [13] led us to challenge this bacterium in another animal model involving inflammation: chemotherapy-induced mucositis [14].

Mucositis is a severe inflammation that affects the Alimentary Tract (AT) of individuals undergoing cancer treatment based on radiotherapy or chemotherapy, such as 5-Flourouracil (5-FU) [15]. Disease is characterized by pathological changes in the small bowel. This includes the presence of degenerative enterocytes, leukocyte infiltrate in the lamina propria, increased mucus production and degeneration of goblet cells, atrophy of villi, hypoplasia and apoptosis of intestinal crypts [16-18]. The side effects are characterized by mucosal injury, inflammation, diarrhea, and weight loss. The currently available treatments of mucositis (cryotherapy, growth factors, anti-inflammatory and antimicrobial agents) are poorly effective and may not be well tolerated. In this context, some studies have proposed the use of probiotic bacterial strains, as promising candidates in the treatment or prevention of inflammatory conditions such as mucositis $[14,19]$. Clinical studies indicate a positive effect of selected lactobacilli in patients with mucositis [20,21], while nothing is known about the effect of probiotic propionibacteria. Accordingly, the MASCC/ISOO (Association of Supportive Care in Cancer/International Society of Oral Oncology) clinical practice guidelines for the management of mucositis secondary to cancer therapy [22] recently added new guidelines, including one suggestion for probiotic agents containing Lactobacillus species for the prevention of chemotherapy and radiationinduced diarrhea in patients with pelvic malignancy as an adjuvant treatment. This comes in addition with the previous guidelines in favor of amifostine, octreotide, sucralfate enemas and sulfasalazine.

The aim of this study is to evaluate the probiotic ability of $P$. freudenreichii CIRM-BIA 129 to protect mice against inflammatory mucositis damages induced by 5 -FU, and to further investigate the impact of $\operatorname{slp} B$ gene mutation on such a protection.

\section{RESULTS}

\section{Propionibacterium freudenreichii WT, yet not the $P$. freudenreichii $\triangle$ slpB mutant, prevents LPS- induced inflammation in HT-29 cells}

We investigated the anti-inflammatory potential of $P$. freudenreichii $\mathrm{WT}$, and the impact of the mutation of the $\operatorname{slp} B$ gene on this potential. HT-29 cells, both in 
the presence and in the absence of proinflammatory Lipopolysaccharide (LPS) from E. coli, were exposed to both strains, WT and mutant. We monitored changes in the relative expression of genes involved in the inflammatory process (Figure 1).

P. freudenreichii WT induced expression of illo (Figure 1A), with significant differences, $(p<0.0001)$, compared to control non-treated cells. The mutant $P$. freudenreichii $\Delta s l p B$ failed to induce il10 expression, by contrast with the WT strain. LPS did not change il10 expression, with or without co-stimulation with $P$. freudenreichii WT or $P$. freudenreichii $\Delta s l p B$. LPS strongly induced il8 (Figure 1B). This induction was inhibited by the presence of $P$. freudenreichii WT, with a significant difference with LPS alone $(\mathrm{p}<0.0001)$, yet not by the mutant $P$. freudenreichii $\Delta s l p B$. As a control, $P$. freudenreichii WT did not induce $i l 8$ expression, while the mutant $P$. freudenreichii $\Delta s l p B$ did, when compared to $P$. freudenreichii WT or to untreated control. Accordingly, both LPS and mutant $P$. freudenreichii $\Delta s l p B$ induced ifna $(\mathrm{p}<0.001)$, while $P$. freudenreichii WT did not (Figure 1C). After LPS stimulus, ifna expression was higher in the presence of the mutant than in the presence of the WT $(\mathrm{p}<0.01)$. The pro-inflammatory tnfa was induced by LPS, yet not by $P$. freudenreichii, neither WT, nor mutant
(Figure 1D). The WT repressed LPS-mediated induction of tnfa, while the mutant did not.

We then monitored expression of TLR2, TLR4 and TLR9 receptors genes. LPS per se had no effect on tlr2 expression (Figure 2A). Contrastingly, P. freudenreichii WT induced expression of tlr2, in comparison with untreated cells $(\mathrm{p}<0.01)$. LPS completely suppressed this tlr2 induction $(\mathrm{p}<0.01)$. The mutant $P$. freudenreichii $\Delta s l p B$ had no significant effect on tlr2 expression.

Concerning tlr4 receptor gene expression (Figure 2B), it was induced by LPS, compared to the untreated control $(\mathrm{p}<0.05)$. The mutant strain also triggered tlr 4 expression significantly, compared to control $(\mathrm{p}<0.0021)$, while $P$. freudenreichii WT did not. This WT strain repressed LPS-induced expression of $\operatorname{tr} 4(\mathrm{p}<0.0001)$, while the mutant strain lost this ability.

Neither LPS, nor $P$. freudenreichii WT modified tlr 9 expression significantly, compared to the control (Figure 2C). In control conditions, $\operatorname{tr} 9$ expression was significantly lower in the presence of the mutant than in the presence of the WT. In LPS-inflamed cells, the opposite was observed with a higher expression in the presence of the mutant than in the presence of the WT $(\mathrm{p}<0.001)$.
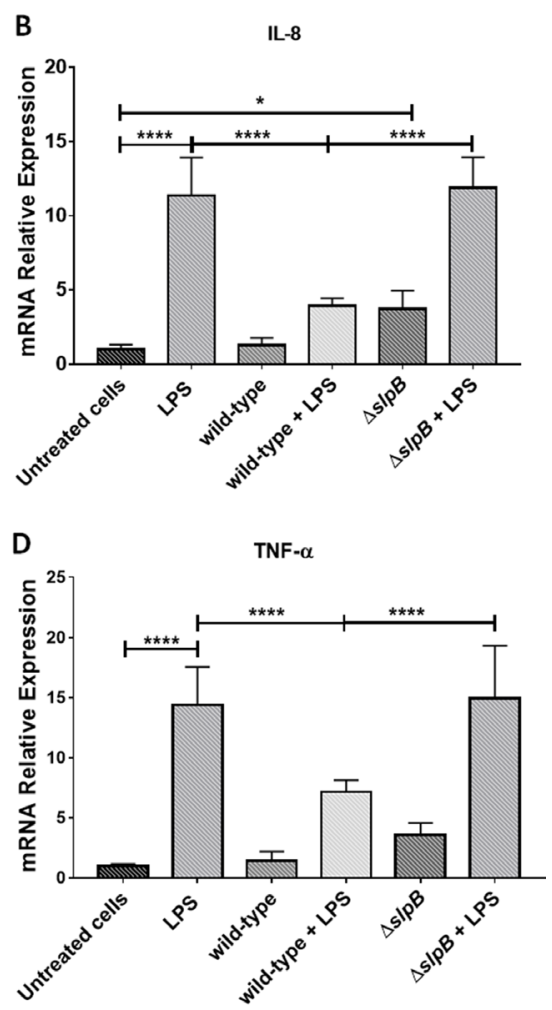

Figure 1: Propionibacterium freudenreichii $\triangle \mathrm{slpB}$ mutant strain induces expression of pro-inflammatory cytokines in HT-29 cells. Relative expression of cytokine genes encoding IL-10 (A), IL-8 (B), TNF- $\alpha$ (C) and IFN- $\alpha$ (D), in HT-29 cells, stimulated by lipopolysaccharides (LPS), P. freudenreichii 129 WT, P. freudenreichii 129 slpB, or combinations thereof, was monitored by RT-PCR. Each cell treatment was done on 3 independent cultures (biological triplicates). Each quantification was done in triplicate (technical triplicates). The means and standard deviations are thus calculated from 9 values. Asterisks represent statistically significant differences between strains and were indicated as follows: $* \mathrm{p}<0.05 ; * * \mathrm{p}<0.01 ; * * * \mathrm{p}<0.001$, and $* * * * \mathrm{p}<0.0001$. 
Regarding tight junction gene zol (Figure 2D) we did not find any significant differences between controls untreated cells and stimulated cells. In LPS-inflamed cells, muc2 (Figure 2E) was more expressed in the presence of the mutant than in the presence of the WT $(p<0.0005)$, while none of these strains affected its expression in control conditions.
A

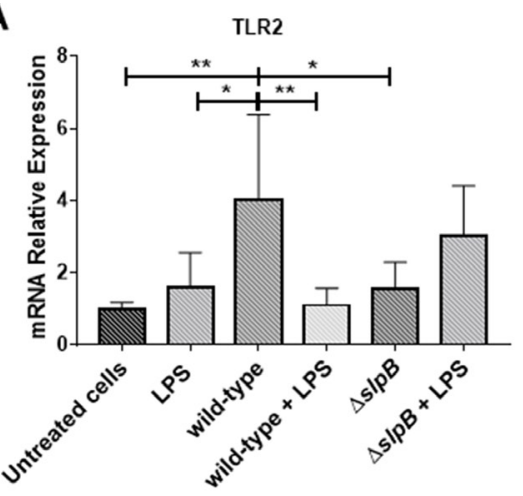

\section{C}

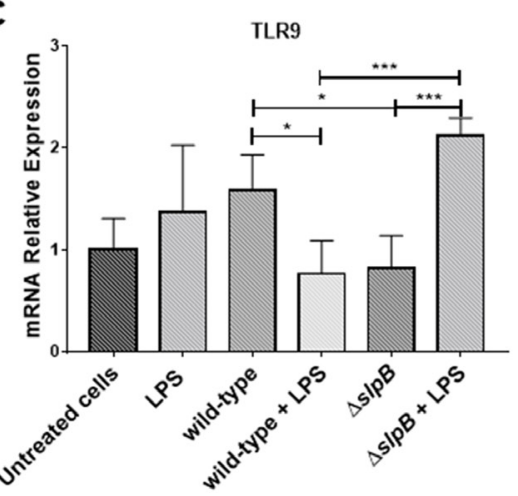

We then extracted surface extractable proteins from P. freudenreichii WT using guanidine hydrochloride and purified the SlpB protein following diafiltration and sizeexclusion chromatography of this extract. The purified protein was then used to stimulate cultivated HT-29 cells. As shown in Supplementary Figure 1, the purified SlpB protein induced $i l 10$ gene expression in HT-29 cells $(\mathrm{p}<0.0005)$.
B

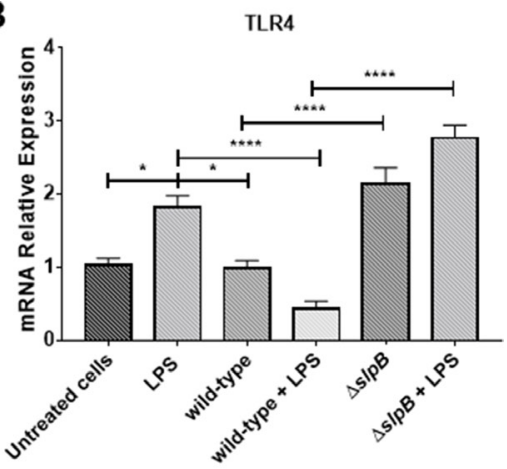

D

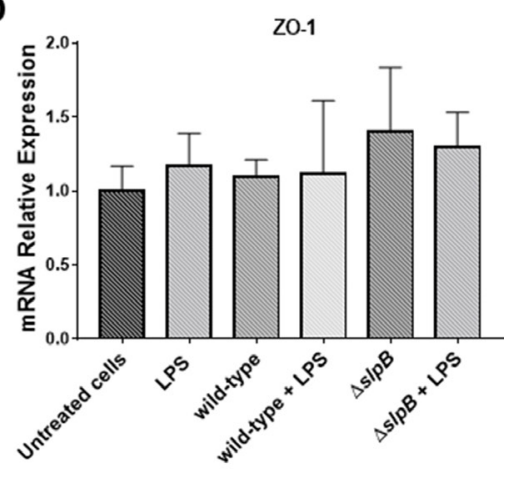

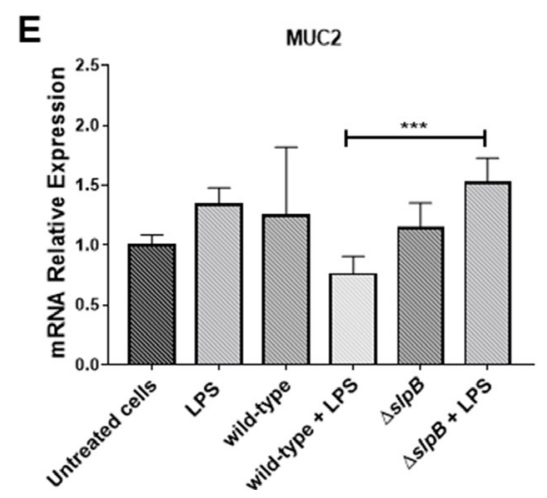

Figure 2: Propionibacterium freudenreichii WT strain modulates in vitro expression of in Toll-like receptors (TLRs) in HT-29 cells. Relative expression of genes encoding TLR2 (A), TLR4 (B), TLR9 (C), ZO1 (D) and of MUC2 (E), in HT-29 cells stimulated by lipopolysaccharides (LPS), P. freudenreichii $129 \mathrm{WT}$, P. freudenreichii $129 \Delta \mathrm{slpB}$, or combinations thereof, was monitored by RT-PCR. Each cell treatment was done on 3 independent cultures (biological triplicates). Each quantification was done in triplicate (technical triplicates). The means and standard deviations are thus calculated from 9 values. Asterisks represent statistically significant differences between strains and were indicated as follows: ${ }^{*} \mathrm{p}<0.05 ; * * \mathrm{p}<0.01 ; * * * \mathrm{p}<0.001$, and $* * * * \mathrm{p}<0.0001$. 


\section{Propionibacterium freudenreichii WT, yet not the $P$. freudenreichii $\Delta s l p B$ mutant, improves mucosal preservation in the ileum of mice treated with 5-FU}

To further evaluate the protective role of probiotic administration in the context of mucositis, the effect of P. freudenreichii on the weight loss of mice after 5-FU administration was studied. The weight of mice belonging to the 8 experimental groups (see Supplementary Figure 2), was monitored before and after 5-FU administration (Figure 3). The body weight in grams as reported in Supplementary Figure 3. No weight difference was observed between groups before 5-FU injection. However, a reduction in weight was clearly observed after 5-FU injection $(\mathrm{p}<0.0001)$, when compared to untreated groups (Figure 3A). In this last group, P. freudenreichii WT strain consumption significantly limited weight loss: $13 \% \pm 1.15(\mathrm{p}<0.001)$, compared to group receiving water: $20.94 \% \pm 3.21$ (Figure 3B). By contrast, the mutant $P$. freudenreichii $\triangle \operatorname{slpB}$ failed to limit weight loss $(19.34 \% \pm 2.58)$, compared to $P$. freudenreichii WT group, $\mathrm{p}<0.05)$.

Although mucositis may affect the whole digestive tract, we examined damages at the ileal level for all mice, as a well-established readout. Regarding histopathological analysis, control groups injected with saline showed no significant difference in ileum mucosal pattern, whether they consumed water, YEL culture medium, or a YEL culture of $P$. freudenreichii WT (Figure 4A). However, consumption of the mutant strain $P$. freudenreichii $\Delta \mathrm{s} l p B$ increased histopathological score (Figure 4A), leading to epithelium flattening, areas of erosion and ulceration in the ileum mucosa (Figure 4B). Moreover, submucosa and muscular layer were thicker than in the other control groups (water, YEL and P. freudenreichii WT). In the submucosa layer, vessels were dilated, and edema intense. Some areas presented focal hemorrhage in the muscular layer. Furthermore, infiltration by immune cells, polymorphonuclear and mononuclear cells, was observed. These damages are further evidenced in Supplementary Figure 4.

Mucositis histopathological score translates the clear changes in the morphological structure of the ileum. This includes the intensity of cells infiltrate in the lamina propria, changes in mucosal architecture and presence of ulceration. In 5-FU-treated groups consuming water and YEL, this corresponded to increased submucosa and muscular layer, villi shortening, epithelium flattening, increased number of inflammatory cells, with diffuse mononuclear polymorphonuclear inflammatory infiltrate in the lamina propria (Figure 4B), when compared to the healthy ileum. Consumption of $P$. freudenreichii WT significantly reduced histopathological scores, compared to control 5-FU-treated groups (water and YEL) $\mathrm{p}<0.001$ (Figure 4A). This corresponded to a reduction in infiltration, in ulceration and in alterations of the intestinal mucosa (Figure 4B, P. freudenreichii WT). The mutant $P$. freudenreichii $\triangle \operatorname{slp} B$, by contrast, failed to alleviate the tissue damages caused by 5-FU (Figure 4B).

In addition, we measured the height of the villi and the depth of the crypts (Figure 5). There was no significant difference between the control groups injected with saline. The 5-FU-treated groups showed a reduction in villus height. Consumption of $P$. freudenreichii WT partially restored this height $(\mathrm{p}>0.0001)$, compared to groups receiving either water or $P$. freudenreichii $\Delta$ slpB (Figure $5 \mathrm{~A}$ ). No significant difference was observed between the 5-FU-treated or non-5-FU-treated groups in terms of crypt depth (Figure 5B).

None of the treatments had a significant effect on the granular density of Paneth cells, in the absence of 5-FU. In the context of 5-FU-mucosistis, granular density was reduced. While the mutant strain had no effect on this reduction, both YEL and P. freudenreichii WT limited this reduction (Figure 5D).
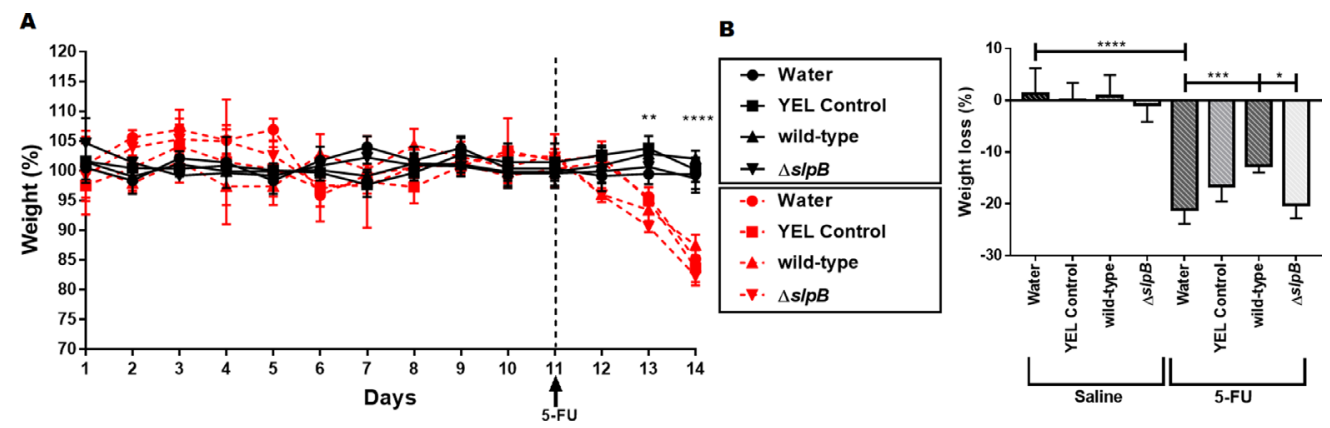

Figure 3: Propionibacterium freudenreichii WT strain prevents weight loss in 5-FU-treated mice. (A) Time-course of body weight for mice receiving YEL culture medium YEL (YEL control), the probiotic strain P. freudenreichii 129 WT (wild-type), or the mutant strain P. freudenreichii $(\Delta s l p B)$. Black lines correspond to the groups injected with saline i.p. and red lines to the groups injected with 5-FU i.p. (B) Weight loss observed after 5-FU injection and differences across groups. The means and standard deviations are calculated from daily weighing of 18 animals per group (Three independent replicates with 6 animals per group). Asterisks represent statistically significant differences as follows: ${ }^{*} \mathrm{p}<0.05 ;{ }^{* *} \mathrm{p}<0.01$; and ${ }^{* * *} \mathrm{p}<0.001$. 


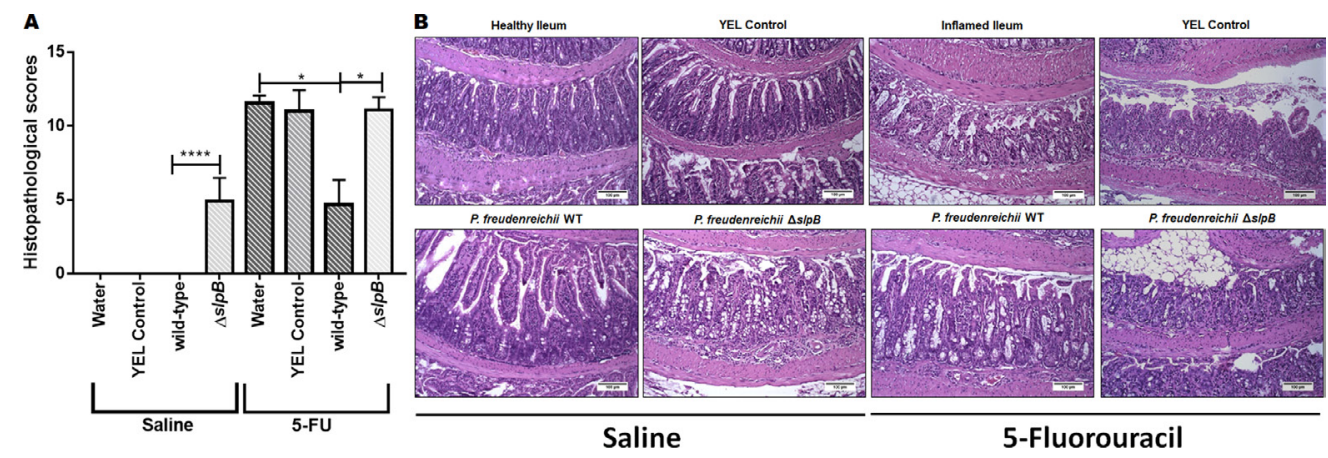

Figure 4: Propionibacterium freudenreichii WT strain alleviates mucosal damage in the ileum of 5-FU-treated mice while mutant strain $P$. freudenreichii $\Delta s l p B$ causes inflammation in healthy mice. (A) Histopathological score obtained in healthy and 5-FU-treated mice. The means and standard deviations are calculated from ileum section of 18 animals per group (Three independent replicates with 6 animals per group). Asterisks represent statistically significant differences as follows: ${ }^{*} \mathrm{p}<0.05 ;{ }^{* *} \mathrm{p}<0.01 ;{ }^{* * *}$ $\mathrm{p}<0.001 ;{ }^{* * * *} \mathrm{p}<0.0001$. and (B) Representative images of H\&E-staining of mice ileal mucosa, demonstrating histopathology. The image acquisition was done with objective magnification at 20x. Scale bar $=100 \mu \mathrm{m}$.
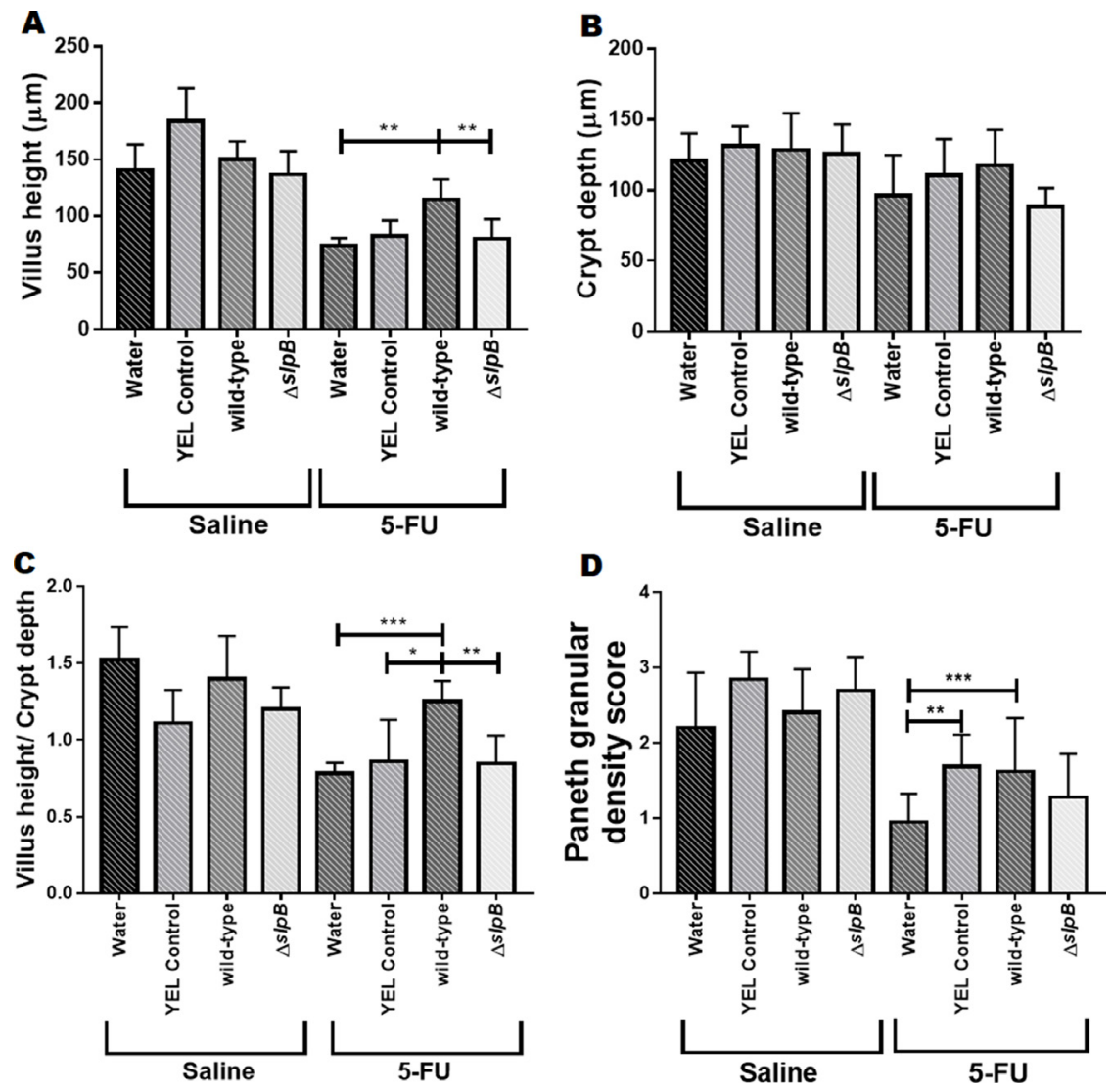

Figure 5: Propionibacterium freudenreichii WT strain protects villus architecture and Paneth cells secretory granules density during 5-FU-induced mucositis. Morphometric analysis of villus height (A), crypt depth (B) and ratio villus height/crypt depth (C) of mice treated with culture media YEL (control), probiotic strain P. freudenreichii WT and mutant strain P. freudenreichii $\triangle s l p B$ or without treatment (water) following 5-FU or saline administration. Microscopic morphometric analysis of Paneth cell secretory granules (D) of mice treated with culture media YEL (control), probiotic strain P. freudenreichii WT and mutant strain P. freudenreichii $\triangle s l p B$ or without treatment (water) following 5-FU or saline administration. Values were obtained using objective magnification at 40x by measuring ten random images of the ileum of mice. The means and standard deviations are calculated from ileum section of 18 animals per group (Three independent replicates with 6 animals per group). Asterisks represent statistically significant differences as follows: $* \mathrm{p}<0.05 ; * *$ $\mathrm{p}<0.01 ; * * * \mathrm{p}<0.001 ; * * * * \mathrm{p}<0.0001$ 
Propionibacterium freudenreichii WT, yet not the P. freudenreichii $\Delta$ slpB mutant, prevents 5-FUinduced gut permeability

Intestinal permeability was evaluated following oral gavage of mice with radiolabeled diethylenetriaminepentaacetate ( $\left.{ }^{99 \mathrm{~m}} \mathrm{Tc}-\mathrm{DTPA}\right)$ and subsequent quantification of radioactivity in the blood. There was no effect of the different treatments on permeability in control conditions (Figure 6, saline). However, as expected, 5-FU injection significantly increased intestinal permeability, as indicated by ${ }^{99 \mathrm{~m}} \mathrm{Tc}-$ DTPA amounts in the mice blood, compared to the control groups (Figure 6, 5-FU water control group). However, the consumption of $P$. freudenreichii WT strain (5-FU wildtype group) significantly prevented $(\mathrm{P}<0.01)$ the $5-\mathrm{FU}-$ induced increase in intestinal permeability. By contrast, consumption of the $P$. freudenreichii mutant strain (5-FU $\triangle \operatorname{slp} B$ group) failed to prevent this induced permeability $(\mathrm{p}<0.2175)$.

\section{Propionibacterium freudenreichii $\Delta$ slpB mutant, yet not the WT strain, induces Th17 cells production in mice spleen}

T-cell subpopulation was evaluated in mice spleen cells by using flow cytometry. As shown in Figure 7 , consumption of the $\Delta \operatorname{slp} B$ mutant strain increased significantly the frequency of both CD4+ ROR- $\gamma \mathrm{t}+\mathrm{T}$ (Figure 7A) and CD4+FOXP3 $+\mathrm{T}$ (Figure 7B) cells subset in the mice spleen, when compared to water control groups $(\mathrm{p}>0.01)$. By contrast, consumption of the WT P. freudenreichii strain did not exerted significant effect on neither of these cell subsets in control conditions $(\mathrm{p}<0.3602 \mathrm{CD} 4+\mathrm{ROR}-\gamma \mathrm{t}+\mathrm{T}$ and $\mathrm{p}<0.1613$ $\mathrm{CD} 4+\mathrm{FOXP} 3+$ ). In 5-FU-treated mice, consumption of the $\triangle \operatorname{slp} B$ mutant resulted in a significant increase in CD4+FOXP3+ and CD4+ ROR- $\gamma \mathrm{t}+\mathrm{T}$ cells $(\mathrm{p}<0.0001$ and $\mathrm{p}<0.0367$ respectively). However, the frequency of CD4+ ROR- $\gamma \mathrm{t}+\mathrm{T}$ cells (Figure 7A) was different between WT and $\triangle \operatorname{sl} p B$ groups only in 5-FU-treated mice $(\mathrm{p}<0.0023)$, suggesting a boosting effect of $\Delta \operatorname{slp} B$ strain upon inflammatory stimulation.

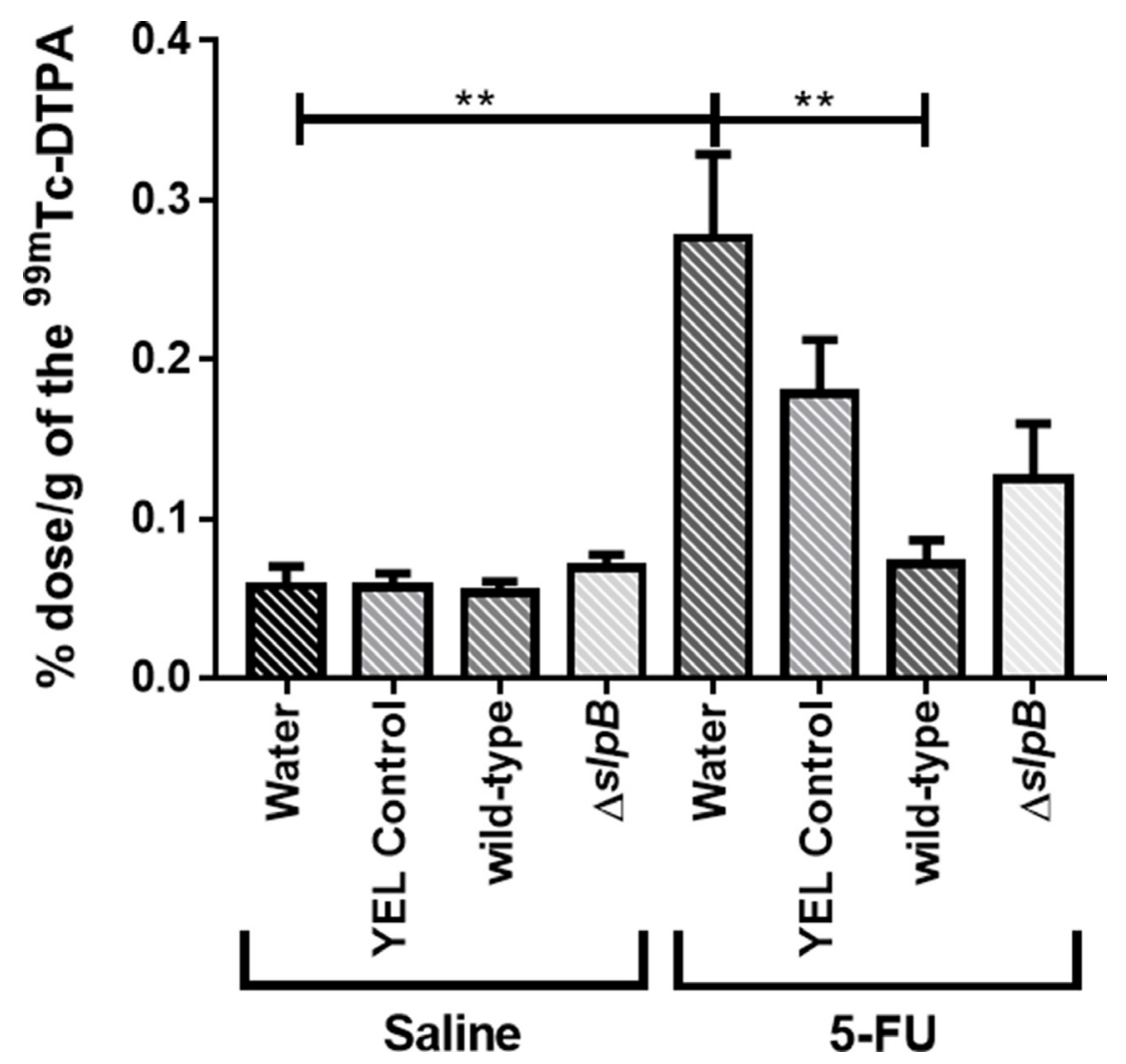

Figure 6: Propionibacterium freudenreichii WT consumption decreases intestinal permeability in 5-FU-treated mice. Intestinal permeability was measured $72 \mathrm{~h}$ after induction of mucositis by radioactivity determination of technetium-99 m ( $99 \mathrm{mTc}-$ DTPA) in mice blood. The means and standard deviations were calculated from one independent experiment for each of the five mice per group. Asterisks represent statistically significant differences between strains and were indicated as follows: ${ }^{*} \mathrm{p}<0.05$; $*$ p $<0.01$; $* * * \mathrm{p}<0.001$, and $* * * * \mathrm{p}<0.0001$. 


\section{Propionibacterium freudenreichii reduces secretory IgA production}

Concentration of secretory $\operatorname{Ig} \mathrm{A}(\mathrm{S} \operatorname{Ig} \mathrm{A})$ in the small intestine of mice, 5-FU-treated and non-5-FU-treated, was measured (Figure 8). Injection of 5-FU increased SIgA, in comparison with untreated mice. This induction was totally suppressed by consumption of both strains. Indeed, both $P$. freudenreichii WT and $P$. freudenreichii $\Delta s l p B$ decreased the amount of SIgA in the 5-FU-treated and non-5-FU-treated groups.

\section{Propionibacterium freudenreichii WT and $\Delta \mathrm{slpB}$ mutant strains differentially modulate gene expression in the mice ileum}

In healthy mice (injected with saline) and in mice injected with 5-FU, no significant difference was found regarding expression of muc2 gene (Figure 9A). Consumption of $P$. freudenreichii WT significantly increased cld1 gene expression levels in mice injected with 5-FU, compared to water $(\mathrm{p}<0.001)$, YEL $(\mathrm{p}<0.05)$ or the mutant P. freudenreichii $\Delta s \operatorname{lp} B(\mathrm{p}<0.001)$ (Figure 9B).
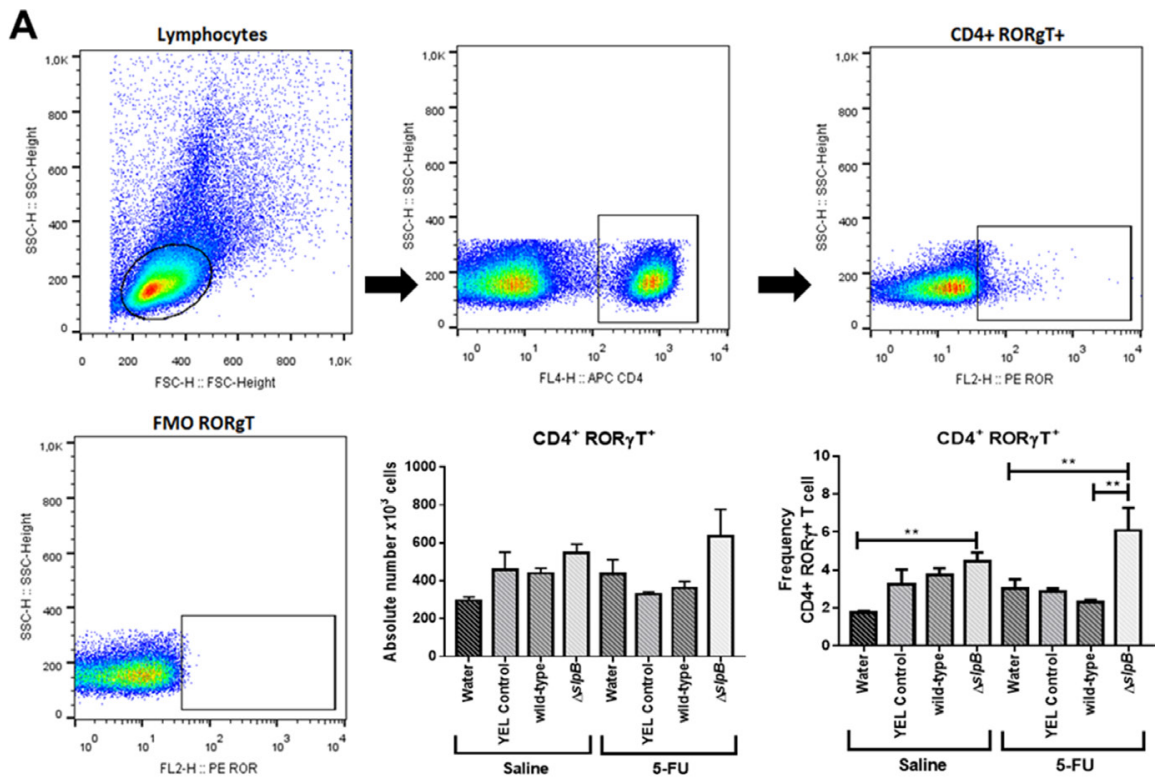

B
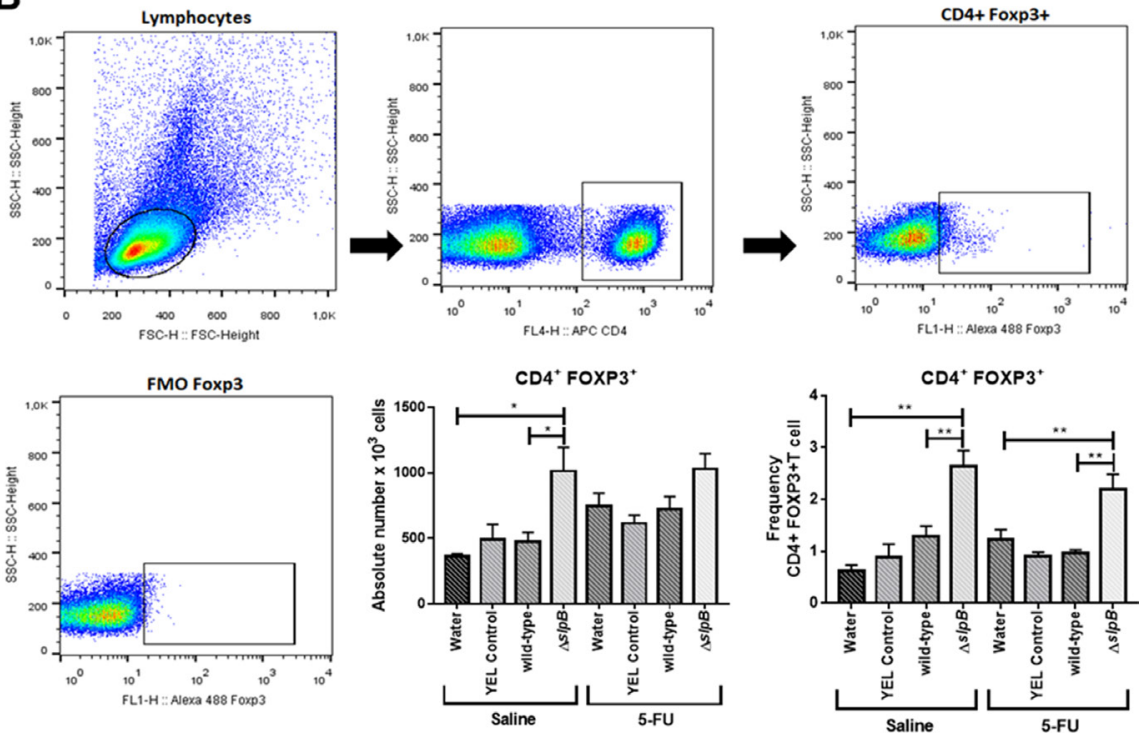

Figure 7: Propionibacterium freudenreichii $\triangle s l p B$ mutant strain induces $T$ lymphocyte production in mice spleen after 5-FU-induced mucositis. $T$ cells were isolated from mice spleen, and the frequencies of (A) CD4+Foxp3+ and (B) CD4+ ROR $\gamma \mathrm{t}+\mathrm{T}$ cells, as frequency (percentage) of CD4+ T cells, were assessed by flow cytometry. The first presented plot represents the gating strategy, based on forward and side scatter, selecting splenocytes as a function of cell size and granularity. Among these, the second presented plot shows gating based on anti-CD4 labeling, selecting $\mathrm{T}$ cells. Then, the third presented plot shows representative gated of populations of ROR $\gamma \mathrm{T}$ (A) and FOXP3 (B) positive T cells. The fluorescence minus one (FMO) control is shown in the fourth plot. The means and standard deviations were calculated from one independent experiment for each of the five mice per group. Asterisks represent statistically significant differences between strains and were indicated as follows: ${ }^{*} \mathrm{p}<0.05 ; *^{*} \mathrm{p}<0.01 ; * * * \mathrm{p}<0.001$, and $* * * * \mathrm{p}<0.0001$. 
Consumption of $P$. freudenreichii $\Delta \operatorname{slpB}$ failed to increase cld1 gene expression. Expression levels of zol only showed significant differences $(\mathrm{p}<0.001)$ between YEL and $P$. freudenreichii WT in heathy mice (saline) (Figure 9C). Expression of Occludin (ocln) was monitored and no significant difference was found (Figure 9D). Expression of iNOS (inducible nitric oxide synthase) was poorly affected, except a trend towards enhanced expression as a result of consumption of the mutant strain, compared to groups receiving water $(\mathrm{p}<0.05)$ and $P$. freudenreichii WT $(\mathrm{p}<0.05)$, in healthy mice (Saline) (Figure 9E). In addition, consumption of the mutant strain induced expression of Il17 in healthy mice $(\mathrm{p}<0.0001)$ (Figure 9F). In 5-FUtreated mice receiving water, 5-FU triggered a significant induction of 1117 , which was mitigated by consumption of YEL medium YEL $(\mathrm{p}<0.01)$ or of the $P$. freudenreichii WT culture $(\mathrm{p}<0.01)$.

\section{Propionibacterium freudenreichii WT and $\Delta$ slpB mutant strains differentially modulate cytokines production in the mice ileum}

Cytokines were quantified by ELISA in the intestinal mucosa of the 5-FU-treated (5-FU) and non-5-FU-treated groups (Saline) (Figure 10). In mucositis conditions
(5-FU), the disease drastically induced all the measured cytokines. Consumption of $P$. freudenreichii WT enhanced the ileal IL-10 concentration in healthy mice $(p<0.05)$. However, no significant effect on IL-10 levels was found in mucositis mice (Figure 10A). IL-12 was enhanced by 5-FU and this 5-FU-induction of IL12 was prevented by consumption of $P$. freudenreichii WT $(\mathrm{p}<0.001)$, when compared to the YEL medium control, while the mutant failed to do so (Figure 10B). None of the treatments affected IL-1 $\beta$ concentration in control healthy mice. In mucositis mice, 5-FU caused an increase in IL-1 $\beta$ concentration. Consumption of $P$. freudenreichii WT however reduced this 5-FU-induction of IL-1 $\beta$ in the context of mucositis $(\mathrm{p}<0.01$, Figure $10 \mathrm{C})$. Finally, consumption of $P$. freudenreichii WT significantly enhanced the ratio of IL-10 to IL-12 ( $<<0.01)$, while the mutant failed to do so (Figure 10D).

\section{DISCUSSION}

The probiotic potential of Propionibacterium freudenreichii is based on both the release of beneficial metabolites [1] and on key surface proteins responsible for interactions with the host $[12,13,23-24]$. S-layer

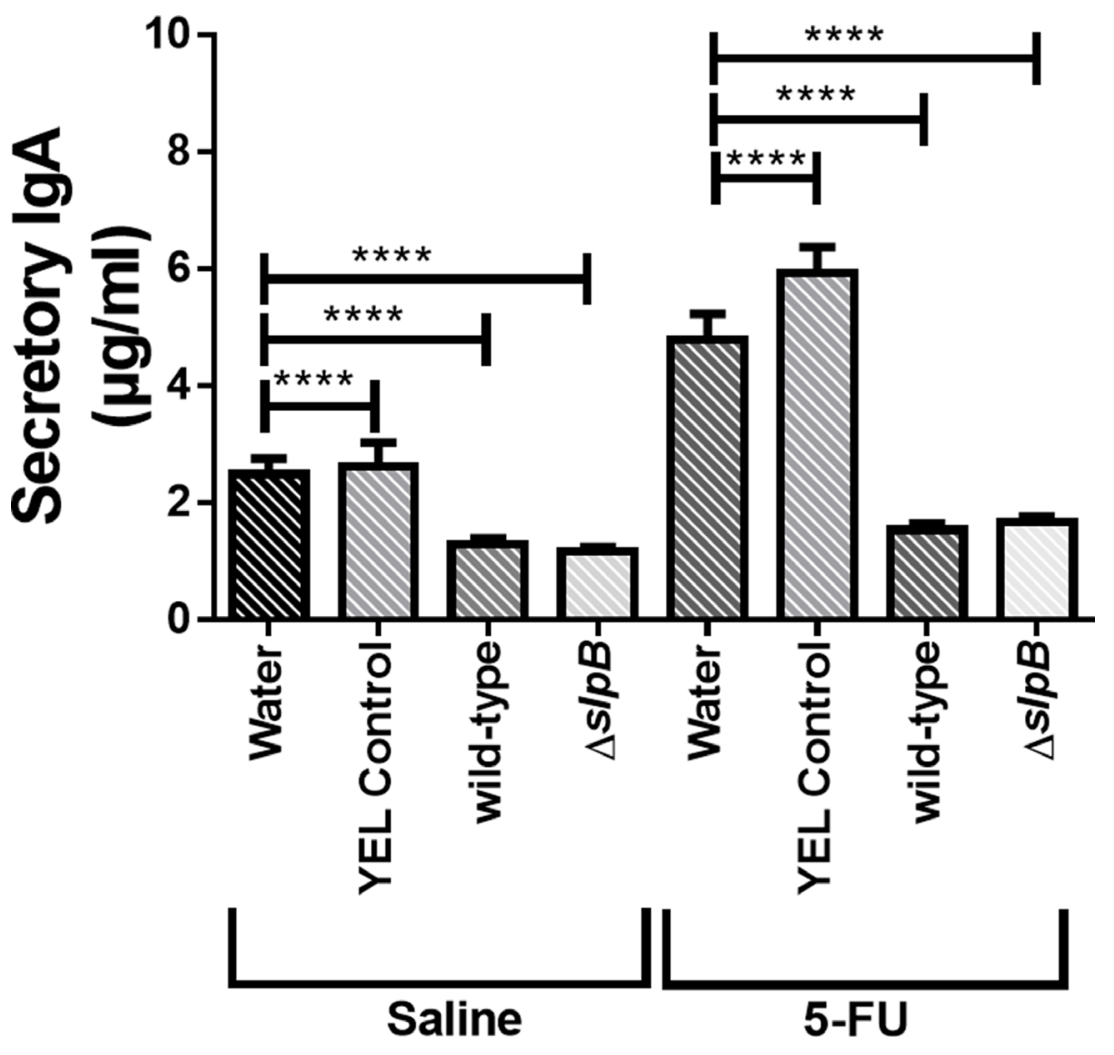

Figure 8: Secretory immunoglobulin A (IgA) in intestinal small bowel content. Quantification of immunoglobulin A secretion (sIgA) in the small intestine of healthy or 5-FU-treated mice. The means and standard deviations are calculated from ileum section of 18 animals per group (Three independent replicates with 6 animals per group). Asterisks represent statistically significant differences as follows: ${ }^{*} \mathrm{p}<0.05 ;{ }^{* *} \mathrm{p}<0.01 ;{ }^{* * *} \mathrm{p}<0.001 ;{ }^{* * * *} \mathrm{p}<0.000$. 

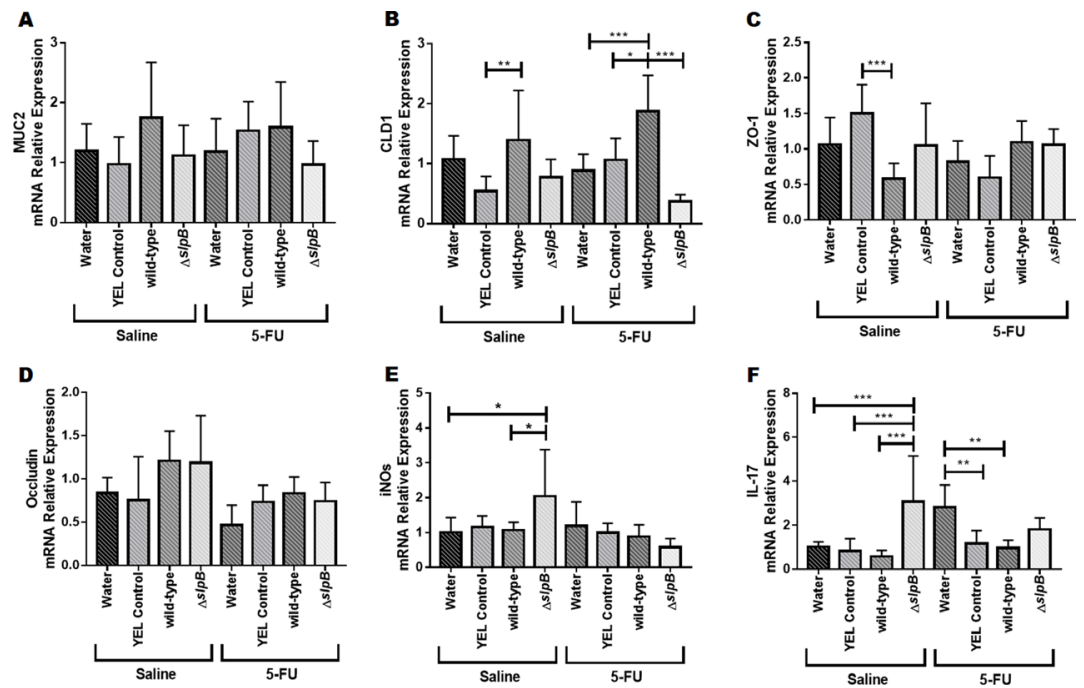

Figure 9: Propionibacterium freudenreichii $\triangle$ slpB induces expression of IL-17 and of inducible NOS (iNOS) in healthy mice. mRNA relative expression of genes (A) $m u c 2$, (B) $c l d 1$, (C) $z o l$, (D) $o c l n$, (E) $i N O S$, and (F) $l l 17$ in mice treated with culture media YEL (control), probiotic strain P. freudenreichii WT and mutant strain P. freudenreichii $\triangle s l p B$ or without treatment (water) following 5-FU or saline administration. Expression levels was monitored by RT-PCR. The means and standard deviations are calculated from 6 animals per group from 3 independent replicates and each quantification was done in triplicate (technical triplicates). Asterisks represent statistically significant differences between strains and were indicated as follows: ${ }^{*} \mathrm{p}<0.05 ; * * \mathrm{p}<0.01 ; * * * \mathrm{p}<0.001$, and ${ }^{* * * *} \mathrm{p}<0.0001$.
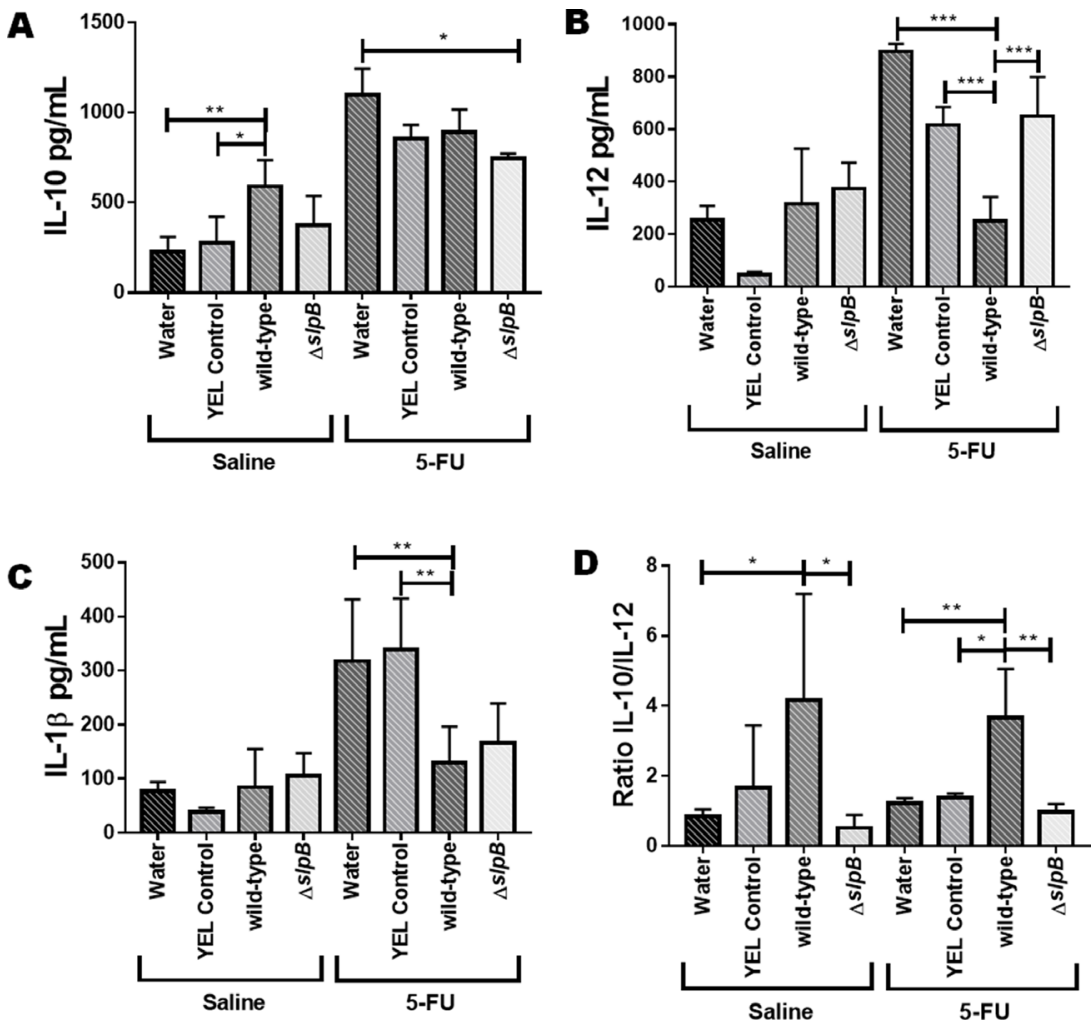

Figure 10: Propionibacterium freudenreichii WT strain reduces the pro-inflammatory cytokine IL-12 production during 5-FU-induced mucositis. The secreted levels of (A) IL-10, (B) IL-12, (C) IL-1 $\beta$, and (D) IL-10/IL-12 ratio were determined in the supernatant of homogenized mice ileum tissue using ELISA. Mice consumed water, YEL culture medium (YEL control), a YEL culture of the probiotic strain P. freudenreichii WT (wild-type) or a YEL culture of the mutant strain $(\triangle s l p B)$. The means and standard deviations are calculated from 6 animals per group from 3 independent replicates and each quantification was done in triplicate (technical triplicates). Asterisks represent statistically significant differences between strains and were indicated as follows: ${ }^{*} \mathrm{p}<0.05 ; * * \mathrm{p}<0.01 ; * * \mathrm{p}<0.001$, and ${ }^{* * * *} \mathrm{p}<0.0001$. 
proteins form a non-covalently anchored surface-exposed proteinaceous network $[25,26]$. They are involved in various processes, such as mediation of the cross-talk with the host [23], which includes immunomodulation [10] and adhesion to host cells in P. freudenreichii [11]. Immunomodulation and adhesion, two processes tightly linked [27], require S-layer-associated proteins in Lactobacilus salivarius REN [28] and in Lactobacillus acidophilus NCFM [29, 30]. In P. freudenreichii WT, adhesion to intestinal human cells requires SlpB [11]. Moreover, mutation of the $\operatorname{slp} B$ gene caused pleotropic effects, impairing surface properties, adhesion and stress tolerance [12]. We therefore investigated the impact of this mutation in the context of human intestinal epithelial cells inflammation.

The present report confirms a key role of SlpB in $P$. freudenreichii probiotic potential. In HT-29 cells, $P$. freudenreichii WT has the ability to induce the release of IL-10, and to reduce that of IL-8 [31]. The ability to induce IL-10 plays a crucial role in the prevention of damage during inflammatory processes $[32,33]$. P. freudenreichii $\triangle \operatorname{slpB}$ strain was shown here to lose this ability to induce IL-10, probably because 1) of the major modifications of the cell surface properties [12] and 2) of reduced adhesion [11]. Accordingly, purified P. freudenreichii SlpB protein induced IL-10 expression in HT-29 cells. Indeed, strains of $P$. freudenreichii which express SlpB induce IL-10 in PBMCs, while those which produce high amounts of SIpA fail to do so [13].

The ability to limit induction of IL- 8 is also important in the anti-inflammatory effect, because IL-8 triggers the recruitment of neutrophils in addition to further pro-inflammatory signals in the lamina propria $[34,35]$. SlpB may also be responsible for the ability to down-regulate IL-8, an anti-inflammatory property shared by several probiotics [36]. Interestingly, the mutant strain, devoid of SlpB, lost the ability to regulate the expression of IL-8, which may decrease their anti-inflammatory potential. This is also observed concerning TNF- $\alpha$, a proinflammatory cytokine, which controls the production of another inflammatory mediator. P. freudenreichii WT repressed TNF- $\alpha$ expression in LPS-stimulated HT-29, as reported for other probiotic bacteria or their culture supernatants $[37,38]$. Again, the mutant strain $P$. freudenreichii $\triangle \operatorname{slpB}$ was unable to inhibit induction of proinflammatory cytokines.

Extractable surface proteins, including Slps, were already shown to mediate immunomodulation in other probiotic bacteria, including L. helveticus MIMLh5 [39], L. acidophilus ATCC4356 [40], L. acidophilus NCFM [41] and L. acidophilus NCK2187 [42]. Other extractable surface proteins are also involved in L. acidophilus NCFM and mutation of the corresponding genes can drastically affect immunomodulatory properties $[43,44]$. Slps of $L$. helveticus NS8 decreased IL12 induction by LPS in mouse macrophage cell line RAW264.7 [45]. Contrastingly, L. helveticus MIMLh5 and its SlpA stimulated the innate immune system by inducing proinflammatory mediators such as TNF $\alpha$ and cyclooxygenase 2 (COX-2) in the human macrophage cell line U937 via TLR2 recognition [39]. Similarly, L. brevis Slps induce TNF $\alpha$ in monocytederived dendritic cells (moDC) [46].

Toll-like receptors participate in the host cells pro-inflammatory response and play a key role in the regulation of the balance between the Th1 and Th2 type of response [47]. Probiotics' anti-inflammatory effects may include modulation of Toll-like receptors (TLRs) [48, 49]. Probiotic bacteria may indeed modulate TLRs in a straindependent manner. P. freudenreichii WT was shown here to enhance TLR2 expression in HT-29 cells, suggesting enhanced reaction towards bacterial LTA, while the mutant failed to do so. In the presence of LPS, no significant effect of $P$. freudenreichii, neither WT nor mutant, was observed regarding TLR2 and TLR9 expression. The pivotal role of the SlpB protein is most evident when monitoring expression of the tlr 4 gene. This expression was shown here to be enhanced by LPS stimulation as previously reported [50]. This induction was totally suppressed by the $P$. freudenreichii wild-type strain, showing another key probiotic ability to impair a pro-inflammatory response machinery. By contrast, LPS-induction of the tlr4 gene was not repressed by the mutant strain.

Probiotic bacteria may modulate TLRs in a straindependent manner. As an example, both L. plantarum BFE 1685 and L. rhamnosus GG up-regulate TLR2 and TLR9 expression in HT-29 cells [51]. L. paracasei F19 strongly induces TLR2 and E. Coli K4-induced TLR4 [52]. L. rhamnosus GG limits the inflammatory response of porcine intestinal epithelial cells exposed to LPS, by modulating TLR expressions and inhibiting MAPK and NF- $\mathrm{B}$ signaling [53]. By contrast, Lactobacillus rhamnosus LGG decreases the expression of TLR2 and TLR-9 in HT-29 cells exposed to Salmonella or ot LPS $[51,53]$. Each probiotic strain has its specific properties and may specifically modulate expression of pro and antiinflammatory cytokines and receptors in HIECs.

Considering the above-mentioned in vitro regulation of key cytokines and receptors by $P$. freudenreichii $\mathrm{WT}$, expressing $\mathrm{SlpB}$, we decided to exploit such immunomodulatory properties, and to address the importance of $\mathrm{SlpB}$, in a preclinical relevant mucositis model. Mucositis is an inflammatory disease that significantly affects cancer patients undergoing antineoplastic chemotherapy such as 5-fluorouracil (5FU). Available treatments for mucositis have limitations and probiotics are considered in this context [19]. $P$. freudenreichii WT was able here to reduce the tissue damages caused by $5-\mathrm{FU}$, to preserve villi height, to limit lamina propria infiltration by inflammatory cells and weight loss, in agreement with other studies showing the efficacy of other probiotics [54-56]. We observed such damages at the ileal level, although mucositis may 
affect the whole digestive tract, as it is a well-established mucositis readout in mice [54-56]. The observed decrease in SIgA levels can be correlated with the protected integrity of the epithelial barrier and consequently protection against pathogens [57-59]. However, mutation of the slpB gene did not change the effect of propionibacteria on sIgA levels. Levels of SIgA increased, when inflammatory stimuli threatened the integrity of the mucosa [58]. They decreased in the group treated with P. freudenreichii WT, suggesting that inflammation was contained.

To further evaluate systemic inflammation, we analyzed CD4+T cells expressing FOXP3+ and ROR $\gamma \mathrm{t}+$ in mice spleens. In accordance with histology and with cytokines modulation, we observed an amplification of the immune process caused by $\Delta \operatorname{slp} B$ mutant strain, with increased frequencies of both $\mathrm{CD} 4+\mathrm{Foxp} 3+$ and CD4+ROR- $\gamma \mathrm{t}+$ cells in spleens of healthy and 5-FUtreated mice. Regulatory $\mathrm{T}$ cells (Tregs) can suppress a wide range of immune cells and play a key role in the maintenance of homeostasis [60], as well as in physiological and pathological immune responses [61]. In our study, the increase in frequency of Tregs might be a compensatory mechanism to counterbalance the cells and mediators of inflammation regarding innate and adaptive cells caused by $\Delta s \operatorname{lp} B$ mutant strain.

It is known that CD4+ ROR- $\gamma \mathrm{t}+$ cells are involved in the pathology of inflammatory bowel diseases such as ulcerative colitis and Crohn's disease [62,63]. It is plausible that, after $\Delta s \operatorname{lp} B$ mutant strain consumption, naïve $\mathrm{T}$ cells start expressing ROR $\gamma \mathrm{t}$, polarizing towards a proinflammatory response via the Th17/IL-17A pathway. IL-17A can modulate the activation and recruitment of neutrophils in the ileum, which is in accordance with the increased histological score and the enhanced expression of the Il-17a gene [64]. In addition, the mutant strain enhanced a subpopulation of CD4+Foxp3+ Treg cells. Regulatory CD4+ T cells expressing Foxp 3 are very abundant throughout the intestinal mucosa and their expansion seems to be a homeostatic default mechanism triggered to control the pro-inflammatory Th17 effector cell response triggered by $\Delta s l p B$ mutant strain, as already described in humans $[65,66]$.

Mucositis induced by 5-FU is linked to an inflammatory process and significantly alters intestinal permeability [67]. We report here that consumption of Propionibacterium freudenreichii WT prevented this alteration, a potential that may prevent the exposition of the host to intestinal toxins and bacteria caused by intestinal permeabilization and thus to systemic inflammation [68]. Induced mucositis is accordingly linked to a reduction in the expression of the Claudin-1 gene [69]. Indeed, the structure of tight junctions is an essential factor of the integrity of the epithelial barrier [70, 71]. No significant effect of the different treatments was observed, regarding the expression of genes encoding ZO-1 and Muc2 proteins. However, treatment with probiotic $P$. freudenreichii WT increased cldl gene expression in the 5-FU-treated group. Claudin-1 is involved in tight junctions formation and in epithelial cells intercellular adhesion [72]. P. freudenreichii WT consumption reduced ileal level of IL-12, which was elevated in the mucositis model [73]. Healthy mice (without 5-FU) consuming $P$. freudenreichii WT (group 1) exhibited enhanced levels of immunomodulatory IL-10, a marker of anti-inflammatory effect also reported for Lactobacillus acidophilus [74]. They exhibited a higher IL-10/IL-12 ratio, which was proposed as an anti-inflammatory probiotic effect marker [75]. Moreover, this ratio was also increased in mice with mucositis consuming $P$. freudenreichii (group 7). It is plausible that IL-10 played a key role in P. freudenreichii WT containing the inflammatory process driven by $5-\mathrm{FU}$, given the importance of this cytokine in gut homeostasis.

Mice receiving $P$. freudenreichii $\Delta s l p B$ exhibited a histopathological score different from those receiving the probiotic strain $P$. freudenreichii WT, but closer to that of mucositis control groups. The mutant lost the ability to maintain architectural integrity of the ileum mucosa. In addition to losing its anti-inflammatory capacity, the mutant strain induced inflammation in the ileum of healthy mice (not receiving 5-FU), in accordance with its inefficacy to protect from mucositis. It failed to reduce the abrupt weight loss caused by 5-FU, in contrast with the probiotic strain. The cld 1 expression, decreased in mucositis, was restored by consumption of the probiotic $P$. freudenreichii WT, but not by the mutant, in accordance with its inability to restore gut permeability. Accordingly, extractable surface proteins are associated with the induction of the expression of tight junctions gene encoding Claudin-1, Occludin, JAM-1, and ZO-1 by other probiotics [23]. Moreover, consumption of the mutant increased ileal expression of iNOS, inducible nitric oxide synthase, an enzyme responsible for the generation of cytotoxic and immunoregulatory free radical $\mathrm{NO}$, which is linked to inflammatory processes [76]. Its expression is triggered by IL-17, a pro-inflammatory T cell cytokine [77]. The ileum contains a great number of IL-17 producing cells [78]. Thus, the induction of both iNOS and IL-17 by the mutant may contribute to the onset of inflammation in healthy mice and to its inability to alleviate mucositis induced by 5 -FU.

\section{MATERIALS AND METHODS}

\section{Bacterial strains and culture conditions}

The wild-type strain $P$. freudenreichii strain ITGP20, equivalent to CIRM-BIA 129 (P. freudenreichii WT), was provided by the CNIEL (Centre National Interprofessionnel de l'Economie Laitière) and maintained by the CIRM-BIA (International Centre for Microbial Resources - Food Associated Bacteria). This strain, as well as the genetically modified $P$. freudenreichii $\Delta s \operatorname{lpB}$ 
strain (P. freudenreichii $\Delta s l p B)$ [11], were grown at $30^{\circ} \mathrm{C}$ in Yeast Extract Lactate (YEL) broth [79]. For the $P$. freudenreichii $\Delta s l p B$ mutant, YEL culture media were supplemented with chloramphenicol $\left(10 \mu \mathrm{g} \cdot \mathrm{mL}^{-1}\right)$. The growth of $P$. freudenreichii was monitored by measuring the optical density at $650 \mathrm{~nm}\left(\mathrm{OD}_{650 \mathrm{~nm}}\right)$, as well as by counting colony-forming units (CFUs) in YEL containing $1.5 \%$ agar, according to Malik and collaborators [79]. Propionibacteria were then used for animal feeding, or harvested in stationary phase $\left(76 \mathrm{~h}, 2 \times 10^{9}\right.$ CFU.mL ${ }^{-1}$, determined by plate counts) by centrifugation $(8,000 \times \mathrm{g}$, $10 \mathrm{~min}, 4^{\circ} \mathrm{C}$ ) and washed in PBS, prior to surface protein extraction, or to HT-29 cells challenging.

\section{Purification of SIpB proteins}

A one-litre culture of $P$. freudenreichii strain ITGP20 was prepared as indicated above. Propionibacteria, washed in PBS, were centrifuged $\left(8,000 \times \mathrm{g}, 10 \mathrm{~min}, 4^{\circ} \mathrm{C}\right)$ and resuspended in $5 \mathrm{M}$ Guanidine hydrochloride (SigmaAldrich, St. Louis, MO, USA). After 15 min of incubation, $50^{\circ} \mathrm{C}$, bacteria were removed by centrifugation $(8,000 \times$ $\mathrm{g}, 10 \mathrm{~min}, 20^{\circ} \mathrm{C}$ ). The resulting Guanidine hydrochloride extract contains surface extractable proteins as previously described [10]. The Guanidine hydrochloride extract was concentrated, with elimination of molecules below $30 \mathrm{kDa}$, by diafiltration using vivaspin $2030,000 \mathrm{MWCO}$ cells (Sartorius, Stonehouse, Gloucestershire, United Kingdom) and following the provided instructions. The concentrated proteins were washed and recovered in PBS buffer using the same diafiltration cells. The resulting extract was separated by FPLC size-exclusion chromatography. An ÄKTA Purifier 10 system (Amersham Biosciences, Uppsala, Sweden) operating at $0.5 \mathrm{~mL} / \mathrm{min}$, equipped with a Superdex 75 10/300 column and a Monitor UV900 detector operating at $280 \mathrm{~nm}$ was used. PBS buffer was used as a mobile phase. The chromatogram and corresponding electrophoretic analysis are shown in Supplementary Figure 1 and Supplementary Figure 5. SlpB, eluted at $11 \mathrm{~mL}$, was then used to stimulate HT-29 cells as described below.

\section{HT-29 cell challenging}

HT-29 cells were routinely grown in T-25 flasks in complete medium DMEMc containing (Dominique Dutscher, Brumath, France) 10\% (v/v) fetal calf serum (PAN-Biotech GmbH, Aidenbach, Germany), $100 \mathrm{U} / \mathrm{mL}$ penicillin and $100 \mu \mathrm{g} / \mathrm{mL}$ streptomycin sulphate) at $37^{\circ} \mathrm{C}$ with $5 \% \mathrm{CO}_{2}$. Trypsin $(0.05 \%)$ /EDTA (0.2\%) (Gibco, Saint Aubin, France) was used to release adherent cells for subculturing. For the experiment, $10^{5}$ cells were seeded in 12 -well plates ( $1 \mathrm{ml}$ of medium per well) and the growth medium was changed every 2 days. HT-29 cells were grown until complete confluence, $1.10^{6}$ cells per well in $1 \mathrm{ml}$ volume. Prior to challenging cells, complete medium was replaced with antibiotic-free medium for 3 hours. HT29 cells were subjected to the different treatments: $7 \mathrm{~h}$ with $100 \mathrm{ng} / \mathrm{mL}$ of Lipopolysaccharide (LPS from E. coli 0111: B4, Sigma), or 7h with $P$. freudenreichii WT, or 7 h with $P$. freudenreichii $\Delta \operatorname{slpB}$. In parallel, cells were also subjected to co-treatments for $7 \mathrm{~h}$ : LPS in combination with $P$. freudenreichii WT or $P$. freudenreichii $\Delta s l p B$, MOI 10 (1 $\mathrm{x}$ $10^{7} \mathrm{CFU}$ per well in $1 \mathrm{ml}$ volume). The percentage of HT29 cells viability after the different stimulation conditions was checked by trypan blue staining and the cells viability was not affected.

\section{HT-29 cell total RNA isolation and gene expression analysis by qRT-PCR}

Cellular RNA was isolated with Trizol reagent (Invitrogen Ambion), and cDNA was synthesized using a qScript cDNA synthesis kit (Quanta Biosciences). Real-time PCR reactions were set up in CFX96 realtime system (Bio-Rad, Marne la Coquette, France). Each PCR reaction was performed in a $16 \mu \mathrm{L}$ reaction mixture containing $5 \mu \mathrm{L}$ SYBR Green PCR Master Mix (Biorad), $5 \mu \mathrm{L}$ of properly diluted cDNA (350 ng of cDNA for all genes), $3 \mu \mathrm{L}$ mixture of each primer (act $\beta$ and gapdh as housekeeping genes, and il8, tnfa, il10, ifna, muc2, zo1, tlr9, tlr4 and tlr2) at $300 \mathrm{nM}$. The negative controls (with no DNA template, only primer pair, water and SYBR Green PCR Master Mix) for each primer set were included in each run. Amplification was carried out using the following program: 3 minutes at $95^{\circ} \mathrm{C}$ and 40 cycles of 2 steps consisting of 5 seconds at $95^{\circ} \mathrm{C}$ and 30 seconds at $60^{\circ} \mathrm{C}$. The relative quantification of the mRNA levels of the target genes was determined using CFX Manager Software. The transcript level was normalized to the transcript level of housekeeping genes encoding $\beta$-actin $($ act $\beta)$ and GAPDH (gapdh). Finally, the results are presented as fold change using $2^{-\Delta \Delta C T}$ method for an unknown sample versus the control (untreated HT29 cells). The sequences of primers used in this study are listed in Table 1. We followed key genes previously reported to translate immunomodulatory response to probiotics in LPS-stimulated intestinal epithelial cells [31, $37,51,53]$. Each cell treatment was done on 3 independent cultures (biological triplicates). Each quantification was done in triplicate (technical triplicates). The means and standard deviations are thus calculated from 9 values.

\section{Evaluation of probiotic properties of P. freudenreichii WT and P. freudenreichii $\triangle$ slpB to prevent mucositis}

\section{Animals}

Conventional female BALB/c mice, between 6 and 8 weeks of age, were obtained at Federal University of Minas Gerais (UFMG-Belo Horizonte, Brazil). These 
Table 1: List of primers used in the in vitro study

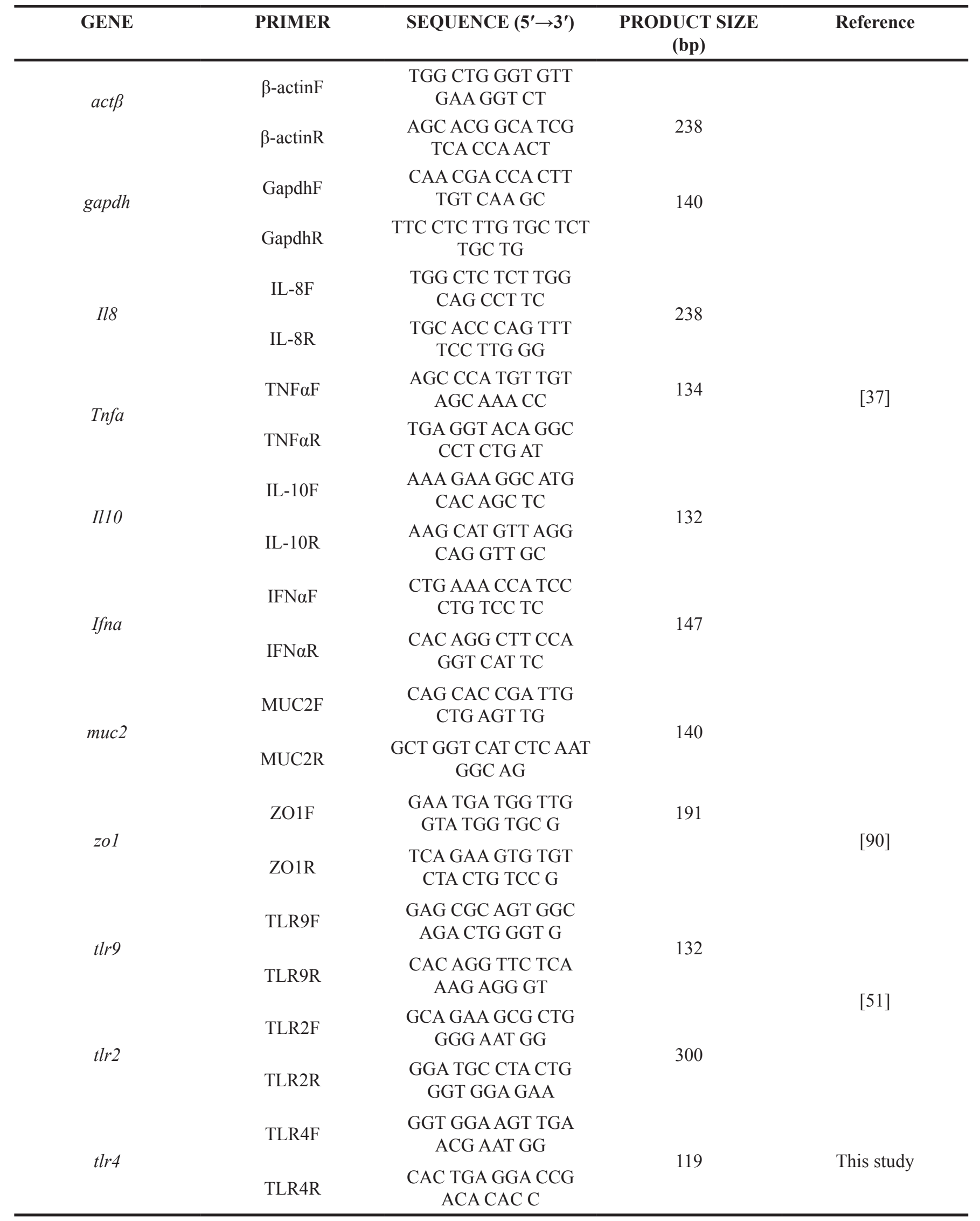

Gene identification, forward and reverse oligonucleotide sequences 5'-3', product size and reference. 
Mice were kept in a temperature-controlled room with ad libitum access to water and standard chow diet. The study was approved by the Ethics Committee on Animal Experimentation of the Federal University of Minas Gerais (CEUA-UFMG, Brazil, protocol 366).

\section{Ethics statement}

This project was approved by the Ethics Committee on Animal Use at Federal University of Minas Gerais (CEUA/UFMG) with protocol no. 366/2012, related to the present study is in agreement with the Ethical Principles in Animal Experimentation, and was approved in $11 / 04 / 2013$.

\section{Experimental set-up}

The experimental set-up is illustrated in Supplementary Figure 1. BALB/c mice were randomly divided into eight groups (6 mice per group). Animals were fed daily orally by $5 \mathrm{~mL}$ of water (groups 1 and 5); $5 \mathrm{~mL}$ of YEL culture medium (groups 2 and 6) or $5 \mathrm{~mL}$ of YEL containg $10^{9} \mathrm{CFU} \mathrm{mL}^{-1}$ of either $P$. freudenreichii WT (groups 3 and 7) or $P$. freudenreichii $\triangle \operatorname{slp} B$ (groups 4 and 8 ) for 10 days. On the eleventh day, the consumption of culture medium and bacteria were discontinued and then all groups received only water. Mucositis was induced on the 11th day of the experimental procedure by a single intraperitoneal injection of 5-fluororacil $(300 \mathrm{mg} /$ $\mathrm{kg}$ ) for groups 5 to 8 . An injection of saline $(\mathrm{NaCl} 0.9 \%)$ was used as a control for groups 1 to 4 [57]. Mice were euthanized on the 14th day. In vivo assays were performed in biological triplicate.

\section{Histological analysis}

For histomorphological analysis, the distal portion of the mice ileum was collected after the euthanasia and washed with PBS. Afterwards, rolls were prepared and immersed in formaldehyde solution $(4 \%, v / v)$ for tissue fixation. This material was embedded in paraffin, and a $4 \mu \mathrm{m}$ section of samples were placed on a glass slide and stained with hematoxylin and eosin (HE). Histological inflammation score was determined as described by MacPherson \& Pfeiffer [80], measuring three major histological changes in mucositis disease: (i) intensity of the infiltrate of mononuclear and polymorphonuclear cells in the lamina propria, (ii) presence of ulceration and erosion and (iii) alterations in mucosal architecture. The score was given according to the severity of the lesion in the tissues: absent (0), mild (1), moderate (2) and severe (3). For morphometric analysis, ten images of the ileum of each animal were randomly captured and analyzed using ImageJ software (version 1.8.0). Granular density of Paneth cells was determined by measuring the intracellular area occupied by secretory granules [57]. Villi height and crypt depth were measured vertically from the tip of villi to the base of the adjacent crypt. Villus height/crypt depth ratio from the intestinal epithelium was also measured [57].

\section{Measurement of secretory $\operatorname{IgA}$}

For measurement of secretory $\operatorname{Ig} \mathrm{A}(\mathrm{sIg} A)$, the small bowel of all euthanized mice were washed using PBS. These materials were vortexed, and centrifuged for $30 \mathrm{~min}$ at $850 \mathrm{~g}$ at $4^{\circ} \mathrm{C}$. Afterwards, the supernatant was transferred to a test tube and used for tested by enzyme-linked immunosorbent assay (ELISA) for IgA concentration as previously described by [57]. The results were expressed as the concentration of $\operatorname{sgA}(\mu \mathrm{g} / \mathrm{ml})$ in intestinal fluid, according to the standard curve.

\section{Flow cytometry analyses of spleen cell subsets}

The method used was previously described by Rocha et al [81]. An amount of $1 \times 10^{6}$ cells were isolated from spleen and resuspended in PBS-BSA-NaN, pH 7.4 (PBS buffer containing $0.2 \%$ BSA (Bovine Serum Albumin) and $0.1 \% \mathrm{NaN}_{3}$ ). Then, cell surface antigens were labeled with CD4 Monoclonal Antibody (GK1.5), APC (eBioscience) for $30 \mathrm{~min}$ at $4^{\circ} \mathrm{C}$. Subsequently, for intracellular staining, cells were fixed and permeabilized with Fixation/ Permeabilization working solution (eBioscience) for one hour on ice prior to incubation with Alexa Fluor ${ }^{\circledR} 488$ Rat Anti-Mouse Foxp3 (BD Pharmingen ${ }^{\mathrm{TM}}$ ) or PE Mouse antiMouse ROR $\gamma \mathrm{t}\left(\mathrm{BD}\right.$ Pharmingen ${ }^{\mathrm{TM}}$ ) for $30 \mathrm{~min}$ at $4^{\circ} \mathrm{C}$. The cells were then washed in PBS-BSA- $\mathrm{NaN}_{3}$ (centrifuged at $1200 \times \mathrm{g}$ for $5 \mathrm{~min}$ at $4^{\circ} \mathrm{C}$ ), and resuspended in $200 \mu \mathrm{L}$ of the same buffer containing $1 \% \mathrm{v} / \mathrm{v}$ paraformaldehyde. Finally, cells were analyzed using a FACS Calibur cytometer (Becton Dickinson, East Rutherford, NJ, USA) and data was analyzed using the FlowJo software (Tree Star, Ashland, OR, USA). At least 10,000 events were counted for each sample. The gating strategy is based on forward and side scatter, then on anti-CD4 labeling, selecting T cells, then on the selection of ROR $\gamma \mathrm{T}$ and of FOXP3 (B) positive T cells. Dead cells were excluded by size and lymphocytes were gated using FSC/SSC analysis. Doublets were excluded using FSC channel (height $\mathrm{x}$ width). FMO was used to set the threshold for labelling superior to isotype control. CD4+ T cells were then gated as previously described [82, 83]. Among these, either $\mathrm{ROR} \gamma \mathrm{T}+\mathrm{e}$ or FOXP $3+$ cells were selected.

\section{Intestinal permeability}

On the last experimental day, after 72 hours of mucositis induction, all animals received $0.1 \mathrm{~mL}$ diethylenetriaminepentaacetate acid (DTPA), labelled with $18,5 \mathrm{MBq}$ of ${ }^{99 m}$ technetium, by gavage. Four hours later, the blood was collected, placed in appropriate tubes for radioactive determination and weighing [67]. Results were calculated as percentage of dose per $\mathrm{g}$ of blood, by the following equation: 
$\%$ dose $/ \mathrm{g}$ blood $=(\mathrm{cpm}$ in $\mathrm{g}$ of blood/cpm dose of standard $) \times$ $100 \mathrm{cpm}$ (counts of radioactivity per minute) [68].

\section{Intestinal tissue preparation and cytokine quantification by ELISA}

For the quantification of cytokines, the ileum were weighed and homogenized in PBS containing $0.05 \%$ Tween-20 (Sigma-Aldrich, St. Louis, MO, USA), phenylmethylsulfonyl fluoride $0.1 \mathrm{mM}$ (Sigma- Aldrich, St. Louis, MO, USA), benzethonium chloride $0.1 \mathrm{mM}$ (Sigma-Aldrich, St. Louis, MO, USA), EDTA $10 \mathrm{mM}$ (Synth, São Paulo, São Paulo, Brazil), and aprotinin A 20 KIU (Sigma-Aldrich, St. Louis, MO, USA). Afterwards, this material was homogenized, centrifuged at 3,000 $\mathrm{g}$ for $10 \mathrm{~min}$ and the supernatants collected for cytokine assay. Plates were coated with purified monoclonal antibodies reactive with cytokines IL- 10, IL-12 p70 and IL-1ß/IL1F2 (R\&D Systems, Inc, USA), overnight at $4^{\circ} \mathrm{C}$. Then, plate wells were washed, supernatants were added, and plates were again incubated overnight at $4^{\circ} \mathrm{C}$. On the third day, biotinylated monoclonal antibodies against cytokines (R\&D Systems, Inc, USA) were added on the plates and incubated for $2 \mathrm{~h}$, at room temperature. Colour was developed at room temperature with $100 \mu \mathrm{l} /$ well of orthophenylenediamine $(1 \mathrm{mg} / \mathrm{ml})$ and $0.04 \%(\mathrm{v} / \mathrm{v})$ $\mathrm{H}_{2} \mathrm{O}_{2}$ substrate in sodium citrate buffer. The reaction was stopped by the addition of $20 \mu \mathrm{l} /$ well of $2 \mathrm{~N} \mathrm{H}_{2} \mathrm{SO}_{4}$. The absorbance was measured at $492 \mathrm{~nm}$ using a Microplate Reader Model 680 (BIO-RAD).

\section{Relative expression of cytokines in mice ileum}

\section{Mice ileum total RNA isolation}

Quantitative expression of genes in ileum tissue was measured according to Oliveira and collaborators [84]. First, small fragments ( $1 \mathrm{~cm}$ approximately) of ileum were collected and stored in RNAlater (Ambion, Austin, USA) at $-80^{\circ} \mathrm{C}$ until RNA extraction. Total RNA was isolated using an RNeasy mini kit (Qiagen, Hilden, Germany) according to the manufacturer's recommended protocol. Residual genomic DNA was digested and removed using DNase I (Invitrogen, Waltham, MA, USA) treatment. Samples were then treated with Turbo DNA-free Kit ${ }^{\circ}$ (Ambion), according to manufacturer's instruction, for DNA removal. cDNA of each sample was produced with High Capacity cDNA Reverse Transcription kit (Applied Biosystems, Foster City, USA), according to its manual instructions.

\section{Mice ileum gene expression analysis by qRT-PCR}

Quantitative PCR (qPCR) was performed using iTaq universal SYBR green supermix (Biorad, Hercules, CA, USA) and gene specific-primers for muc2, Claudin-1 (cld1), Tjp1, Occludin (ocln), iNOS and il-17a [85-88] as well as housekeeping genes encoding $\beta$-actin $(a c t \beta)$ and GAPDH (gapdh) [85]. Amplification reactions were performed in a final volume of $10 \mu \mathrm{l}$, using $5 \mu \mathrm{l}$ of SYBR green supermix and $10 \mathrm{ng}$ of cDNA. The amplification program consisted of the following steps: $95^{\circ} \mathrm{C}$ for 30 sec, and 40 cycles of $95^{\circ} \mathrm{C}$ for $15 \mathrm{sec}$ and $60^{\circ} \mathrm{C}$ for $30 \mathrm{sec}$ on an ABI PRISM 7900HT Sequence Detection System (Applied Biosystems, Foster City, CA). Expression levels in control group (with no treatment) were used as calibration data. Results are shown graphically as fold changes in gene expression, using the means and standard deviations of target cytokine expression amount $\left(2^{-\Delta \Delta C t}\right)$ according to Hellemans, Mortier, De Paepe, Speleman, and Vandesompele (2007) [89]. We monitored expression of key genes previously reported to translate severity of intestinal damages in mice $[9,86-88]$.

\section{Statistical analyses}

The results were reported as the mean \pm standard deviation. Parametric data's were analyzed using OneWay ANOVA followed by the Tukey or Sidak post-test. Non-parametric data's were analyzed using KruskalWallis data followed by the Dunns post-test. Graphs and statistical analyzes were performed in GraphPad Prism version 7.00 for Windows (GraphPad Software, San Diego, California, U.S.A.). Asterisks represent statistically significant differences between strains and were indicated as follows: ${ }^{*} \mathrm{p}<0.05 ;{ }^{* *} \mathrm{p}<0.01 ;{ }^{* * *} \mathrm{p}<0.001$ and ${ }^{* * * *} \mathrm{p}<0.0001$.

\section{CONCLUSIONS}

This study confirmed the anti-inflammatory effects of $P$. freudenreichii strain ITGP20, equivalent to CIRM-BIA 129. In the context of induced mucositis, this probiotic reduced inflammation, limited histopathological damages, and restored intestinal permeability. This is important in the context of chemotherapy-induced mucositis, to prevent possible translocation of pathogens and systemic inflammation and infection. This work moreover demonstrated, by in vitro and in vivo approaches, that the mutation of the extractable surface protein $s l p B$ gene affects directly the probiotic effects of P. freudenreichii. This is mainly evidenced by the fact that P. freudenreichii $\Delta \operatorname{slpB}$ loses its ability to regulate proinflammatory cytokines in LPS stimulated HT-29 cells, and to alleviate 5-FU induced mucositis. This opens new perspectives for exploring S-layer proteins as possible adjuvants in the treatment of mucositis. Understanding the mechanism responsible for this protective effects deepens the knowledge of Propionibacteria immunomodulatory properties. It opens new perspectives for the utilization of this strain, or of extracted SlpB, in order to alleviate the inflammatory process of mucositis. The clinical guidelines for the management of mucositis recently added a suggestion for the use of probiotics. 
P. freudenreichii, to our knowledge, received the GRAS status for its use in cheese, for a healthy population. The safety of its consumption by cancer patients with compromised immunity and mucosal barrier should be investigated in this aim. Moreover, metagenomic studies should address the impact on the structure and activity of the gut microbiota, given that selected $P$. freudenreichii strains produce bifidogenic factors and other nutraceutical compounds that may modulate the commensal microbiota.

\section{Abbreviations}

DC-SIGNR1: dendritic cell-specific intercellular adhesion molecule-3-grabbing non-integrin; HIEC: human intestinal epithelial cell; LPS: lipopolysaccharides; PBMC: peripheral blood mononuclear cell; RT-PCR: reverse transcription-polymerase chain reaction; SLAP: S-layer associated protein; SLH: S-layer homology domain; Slp: surface-layer protein; TLR: toll-like receptor.

\section{Author contributions}

FLRdC performed all the experimental design and had a major contribution to the whole experimentation, to data analysis and interpretation, and to the writing of the manuscript. BFC, SHdS, BS, AF, LL, JdLA, CCF, MIAQ, ERO and SHdCS were major contributors to animal experimentation, cytokines measurement, quantitative PCR, flow cytometry analysis and performed, analyzed and interpreted the secretory $\operatorname{IgA}$ quantification essay. EF and NMR performed, analyzed and interpreted the morphometric analysis and histological analysis from ileum slides. HR performed in vitro analysis and data interpretation. AMCF, ACN, YLL, GJ and VA contributed to data interpretation and to writing the manuscript. RMP, SOAF and VNC were involved in permeability assays. VG and MD in protein purification and in RT-Q-PCR. GJ and VA, have equally contributed to the supervision of the work.

\section{ACKNOWLEDGMENTS}

The authors thank Keiju Min-Ahs and Annabelle Deschamps for expert technical assistance and for useful discussions and advices. Lastly, we would also like thank CNIEL (Centre National Interprofessionnel de l'Economie Laitière) for providing the ITGP20 strain.

\section{CONFLICTS OF INTEREST}

The authors declare that the research was conducted in the absence of any commercial or financial relationships that could be construed as a potential conflict of interest. We declare no competing interest, no conflict of interest, neither financial, nor non-financial.

\section{FUNDING}

This work was supported by Conselho Nacional de Desenvolvimento Científico e Tecnológico (CNPq), Fundação de Amparo à Pesquisa do Estado de Minas Gerais (FAPEMIG), Coordenação de Aperfeiçoamento de Pessoal de Nível Superior (CAPES), and Région Bretagne (BZH). Houem Rabah was the recipient of a $\mathrm{PhD}$ fellowship co-financed by ANRT (French National Association of Research and Technology) and by Pôle Agronomique Ouest.

\section{REFERENCES}

1. Rabah H, Rosa do Carmo FL, Jan G. Dairy Propionibacteria: versatile Probiotics. Microorganisms. 2017; 5. https://doi. org/10.3390/microorganisms5020024. [PubMed]

2. Cousin FJ, Mater DD, Foligne B, Jan G. Dairy propionibacteria as human probiotics: A review of recent evidence. Dairy Sci Technol. 2010; 91: 1-26. https://doi. org/10.1051/dst/2010032.

3. Mogensen G, Salminen S, O'Brien J, Ouwenhand A, Holzapfel W, Shortt C, Fonden R, Miller GD, Donohue D, Playne MJ, Crittenden RG, Biannchi-Salvadori B, Zink R. Inventory of microoganisms with a documented history of use in food. 2002; 10-19. https://hdl.handle.net/102.100.10 0/197230? index $=1$.

4. Cousin FJ, Foligné B, Deutsch SM, Massart S, Parayre S, Le Loir Y, Boudry G, Jan G. Assessment of the probiotic potential of a dairy product fermented by Propionibacterium freudenreichii in piglets. J Agric Food Chem. 2012; 60: 7917-27. https://doi.org/10.1021/jf302245m. [PubMed]

5. Foligné B, Deutsch SM, Breton J, Cousin FJ, Dewulf J, Samson M, Pot B, Jan G. Promising immunomodulatory effects of selected strains of dairy propionibacteria as evidenced in vitro and in vivo. Appl Environ Microbiol. 2010; 76: 8259-64. https://doi.org/10.1128/AEM.0197610. [PubMed]

6. Oksaharju A, Kooistra T, Kleemann R, van Duyvenvoorde W, Miettinen M, Lappalainen J, Lindstedt KA, Kovanen PT, Korpela R, Kekkonen RA. Effects of probiotic Lactobacillus rhamnosus GG and Propionibacterium freudenreichii ssp. shermanii JS supplementation on intestinal and systemic markers of inflammation in ApoE*3Leiden mice consuming a high-fat diet. Br J Nutr. 2013; 110: 77-85. https://doi. org/10.1017/S0007114512004801. [PubMed]

7. Kajander K, Myllyluoma E, Rajilić-Stojanović M, Kyrönpalo S, Rasmussen M, Järvenpää S, Zoetendal EG, de Vos WM, Vapaatalo H, Korpela R. Clinical trial: multispecies probiotic supplementation alleviates the symptoms of irritable bowel syndrome and stabilizes intestinal microbiota. Aliment Pharmacol Ther. 2008; 27 : 48-57. https://doi.org/10.1111/j.1365-2036.2007.03542.x. [PubMed] 
8. Plé C, Richoux R, Jardin J, Nurdin M, Briard-Bion V, Parayre S, Ferreira S, Pot B, Bouguen G, Deutsch SM, Falentin H, Foligné B, Jan G. Single-strain starter experimental cheese reveals anti-inflammatory effect of Propionibacterium freudenreichii CIRM BIA 129 in TNBScolitis model. J Funct Foods. 2015; 18: 575-85. https://doi. org/10.1016/j.jff.2015.08.015.

9. Plé C, Breton J, Richoux R, Nurdin M, Deutsch SM, Falentin H, Hervé C, Chuat V, Lemée R, Maguin E, Jan G, Van de Guchte M, Foligné B. Combining selected immunomodulatory Propionibacterium freudenreichii and Lactobacillus delbrueckii strains: reverse engineering development of an anti-inflammatory cheese. Mol Nutr Food Res. 2016; 60: 935-48. https://doi.org/10.1002/ mnfr.201500580. [PubMed]

10. Le Maréchal C, Peton V, Plé C, Vroland C, Jardin J, Briard-Bion V, Durant G, Chuat V, Loux V, Foligné B, Deutsch SM, Falentin H, Jan G. Surface proteins of Propionibacterium freudenreichii are involved in its antiinflammatory properties. J Proteomics. 2015; 113: 447-61. https://doi.org/10.1016/j.jprot.2014.07.018. [PubMed]

11. do Carmo FL, Rabah H, Huang S, Gaucher F, Deplanche M, Dutertre S, Jardin J, Le Loir Y, Azevedo V, Jan G. Propionibacterium freudenreichii Surface Protein SlpB Is Involved in Adhesion to Intestinal HT-29 Cells. Front Microbiol. 2017; 8: 1033. https://doi.org/10.3389/ fmicb.2017.01033. [PubMed]

12. do Carmo FL, Silva WM, Tavares GC, Ibraim IC, Cordeiro BF, Oliveira ER, Rabah H, Cauty C, da Silva $\mathrm{SH}$, Canário Viana MV, Caetano AC, Dos Santos RG, de Oliveira Carvalho RD, et al. Mutation of the surface layer protein SlpB has pleiotropic effects in the probiotic Propionibacterium freudenreichii CIRM-BIA 129. Front Microbiol. 2018; 9: 1807. https://doi.org/10.3389/ fmicb.2018.01807. [PubMed]

13. Deutsch SM, Mariadassou M, Nicolas P, Parayre S, Le Guellec R, Chuat V, Peton V, Le Maréchal C, Burati J, Loux V, Briard-Bion V, Jardin J, Plé C, et al. Identification of proteins involved in the anti-inflammatory properties of Propionibacterium freudenreichii by means of a multi-strain study. Sci Rep. 2017; 7: 46409. https://doi.org/10.1038/ srep46409. [PubMed]

14. do Carmo FLR, Rabah H, Fernandes Cordeiro B, Da Silva SH, Jan G, Azevedo VA, de Oliveira Carvalho RD. Applications of Probiotic Bacteria and Dairy Foods in Health. Current Research in Microbiology. Open Access eBooks 919 North Market Street Suite 425 Wilmington, DE 19801; 2017. p. 1-33.

15. Sonis ST. The pathobiology of mucositis. Nat Rev Cancer. 2004; 4: 277-84. https://doi.org/10.1038/nrc1318. [PubMed]

16. Antunes MM, Leocádio PC, Teixeira LG, Leonel AJ, Cara DC, Menezes GB, Generoso SV, Cardoso VN, AlvarezLeite JI, Correia MI. Pretreatment With L-Citrulline Positively Affects the Mucosal Architecture and
Permeability of the Small Intestine in a Murine Mucositis Model. JPEN J Parenter Enteral Nutr. 2016; 40: 279-86. https://doi.org/10.1177/0148607114567508. [PubMed]

17. Chang CT, Ho TY, Lin H, Liang JA, Huang HC, Li CC, Lo HY, Wu SL, Huang YF, Hsiang CY. 5-Fluorouracil induced intestinal mucositis via nuclear factor- $\kappa \mathrm{B}$ activation by transcriptomic analysis and in vivo bioluminescence imaging. PLoS One. 2012; 7: e31808. https://doi. org/10.1371/journal.pone.0031808. [PubMed]

18. Stringer AM. Interaction between host cells and microbes in chemotherapy-induced mucositis. Nutrients. 2013; 5: 1488-99. https://doi.org/10.3390/nu5051488. [PubMed]

19. Carvalho RD, do Carmo FL, de Oliveira Junior A, Langella P, Chatel JM, Bermúdez-Humarán LG, Azevedo V, de Azevedo MS. Use of wild type or recombinant Lactic Acid Bacteria as an alternative treatment for gastrointestinal inflammatory diseases: A focus on Inflammatory Bowel Diseases and Mucositis. Front Microbiol. 2017; 8: 800. https://doi.org/10.3389/fmicb.2017.00800. [PubMed]

20. Cereda E, Caraccia M, Caccialanza R. Probiotics and mucositis. Curr Opin Clin Nutr Metab Care. 2018; 21: 399404. [PubMed]

21. Bowen JM, Gibson RJ, Coller JK, Blijlevens N, Bossi P, Al-Dasooqi N, Bateman EH, Chiang K, de Mooij C, Mayo B, Stringer AM, Tissing W, Wardill HR, et al, and Mucositis Study Group of the Multinational Association of Supportive Care in Cancer/International Society of Oral Oncology (MASCC/ISOO). Systematic review of agents for the management of cancer treatment-related gastrointestinal mucositis and clinical practice guidelines. Support Care Cancer. 2019; 27: 4011-22. https://doi.org/10.1007/s00520019-04892-0. [PubMed]

22. Lalla RV, Bowen J, Barasch A, Elting L, Epstein J, Keefe DM, McGuire DB, Migliorati C, Nicolatou-Galitis O, Peterson DE, Raber-Durlacher JE, Sonis ST, Elad S, and Mucositis Guidelines Leadership Group of the Multinational Association of Supportive Care in Cancer and International Society of Oral Oncology (MASCC/ISOO). MASCC/ISOO clinical practice guidelines for the management of mucositis secondary to cancer therapy. Cancer. 2014; 120: 1453-61. https://doi.org/10.1002/cncr.28592. [PubMed]

23. do Carmo FL, Rabah H, De Oliveira Carvalho RD, Gaucher F, Cordeiro BF, da Silva SH, Le Loir Y, Azevedo V, Jan G. Extractable Bacterial Surface Proteins in Probiotic-Host Interaction. Front Microbiol. 2018; 9: 645. https://doi. org/10.3389/fmicb.2018.00645. [PubMed]

24. Colliou N, Ge Y, Sahay B, Gong M, Zadeh M, Owen JL, Neu J, Farmerie WG, Alonzo F 3rd, Liu K, Jones DP, Li S, Mohamadzadeh M. Commensal Propionibacterium strain UF1 mitigates intestinal inflammation via Th17 cell regulation. J Clin Invest. 2017; 127: 3970-86. https://doi. org/10.1172/JCI95376. [PubMed]

25. Gerbino E, Carasi P, Mobili P, Serradell MA, GómezZavaglia A. Role of S-layer proteins in bacteria. World 
J Microbiol Biotechnol. 2015; 31: 1877-87. https://doi. org/10.1007/s11274-015-1952-9. [PubMed]

26. Sleytr UB, Schuster B, Egelseer EM, Pum D. S-layers: principles and applications. FEMS Microbiol Rev. 2014; 38: 823-64. https://doi.org/10.1111/1574-6976.12063. [PubMed]

27. Preising J, Philippe D, Gleinser M, Wei H, Blum S, Eikmanns BJ, Niess JH, Riedel CU. Selection of bifidobacteria based on adhesion and anti-inflammatory capacity in vitro for amelioration of murine colitis. Appl Environ Microbiol. 2010; 76: 3048-51. https://doi. org/10.1128/AEM.03127-09. [PubMed]

28. Wang R, Jiang L, Zhang M, Zhao L, Hao Y, Guo H, Sang Y, Zhang H, Ren F. The Adhesion of Lactobacillus salivarius REN to a Human Intestinal Epithelial Cell Line Requires S-layer Proteins. Sci Rep. 2017; 7: 44029. https://doi. org/10.1038/srep44029. [PubMed]

29. Johnson BR, Klaenhammer TR. AcmB Is an S-LayerAssociated $\beta$-N-Acetylglucosaminidase and Functional Autolysin in Lactobacillus acidophilus NCFM. Appl Environ Microbiol. 2016; 82: 5687-97. https://doi. org/10.1128/AEM.02025-16. [PubMed]

30. Hymes JP, Johnson BR, Barrangou R, Klaenhammer TR. Functional Analysis of an S-Layer-Associated FibronectinBinding Protein in Lactobacillus acidophilus NCFM. Appl Environ Microbiol. 2016; 82: 2676-85. https://doi. org/10.1128/AEM.00024-16. [PubMed]

31. Rabah H, Ménard O, Gaucher F, do Carmo FL, Dupont D, Jan G. Cheese matrix protects the immunomodulatory surface protein SlpB of Propionibacterium freudenreichii during in vitro digestion. Food Res Int. 2018; 106: 712-21. https://doi.org/10.1016/j.foodres.2018.01.035. [PubMed]

32. Denning TL, Campbell NA, Song F, Garofalo RP, Klimpel GR, Reyes VE, Ernst PB. Expression of IL-10 receptors on epithelial cells from the murine small and large intestine. Int Immunol. 2000; 12: 133-9. https://doi.org/10.1093/ intimm/12.2.133. [PubMed]

33. Jarry A, Bossard C, Bou-Hanna C, Masson D, Espaze E, Denis MG, Laboisse CL. Mucosal IL-10 and TGF-beta play crucial roles in preventing LPS-driven, IFN-gammamediated epithelial damage in human colon explants. J Clin Invest. 2008; 118: 1132-42. https://doi.org/10.1172/ JCI32140. [PubMed]

34. Kucharzik T, Hudson JT 3rd, Lügering A, Abbas JA, Bettini M, Lake JG, Evans ME, Ziegler TR, Merlin D, Madara JL, Williams IR. Acute induction of human IL-8 production by intestinal epithelium triggers neutrophil infiltration without mucosal injury. Gut. 2005; 54: 1565-72. https:// doi.org/10.1136/gut.2004.061168. [PubMed]

35. Singer M, Sansonetti PJ. IL-8 is a key chemokine regulating neutrophil recruitment in a new mouse model of Shigellainduced colitis. J Immunol. 2004; 173: 4197-206. https:// doi.org/10.4049/jimmunol.173.6.4197. [PubMed]
36. Bai AP, Ouyang Q, Zhang W, Wang CH, Li SF. Probiotics inhibit TNF-alpha-induced interleukin-8 secretion of HT29 cells. World J Gastroenterol. 2004; 10: 455-57. https://doi. org/10.3748/wjg.v10.i3.455. [PubMed]

37. Duary RK, Batish VK, Grover S. Immunomodulatory activity of two potential probiotic strains in LPS-stimulated HT-29 cells. Genes Nutr. 2014; 9: 398. https://doi. org/10.1007/s12263-014-0398-2. [PubMed]

38. Ménard S, Candalh C, Bambou JC, Terpend K, CerfBensussan N, Heyman M. Lactic acid bacteria secrete metabolites retaining anti-inflammatory properties after intestinal transport. Gut. 2004; 53: 821-28. https://doi. org/10.1136/gut.2003.026252. [PubMed]

39. Taverniti V, Stuknyte M, Minuzzo M, Arioli S, De Noni I, Scabiosi C, Cordova ZM, Junttila I, Hämäläinen S, Turpeinen H, Mora D, Karp M, Pesu M, Guglielmetti $\mathrm{S}$. S-layer protein mediates the stimulatory effect of Lactobacillus helveticus MIMLh5 on innate immunity. Appl Environ Microbiol. 2013; 79: 1221-31. https://doi. org/10.1128/AEM.03056-12. [PubMed]

40. Li P, Yu Q, Ye X, Wang Z, Yang Q. Lactobacillus S-layer protein inhibition of Salmonella-induced reorganization of the cytoskeleton and activation of MAPK signalling pathways in Caco-2 cells. Microbiology. 2011; 157: 263946. https://doi.org/10.1099/mic.0.049148-0. [PubMed]

41. Konstantinov SR, Smidt H, de Vos WM, Bruijns SC, Singh SK, Valence F, Molle D, Lortal S, Altermann E, Klaenhammer TR, van Kooyk Y. S layer protein A of Lactobacillus acidophilus NCFM regulates immature dendritic cell and T cell functions. Proc Natl Acad Sci U S A. 2008; 105: 19474-79. https://doi.org/10.1073/ pnas.0810305105. [PubMed]

42. Lightfoot YL, Selle K, Yang T, Goh YJ, Sahay B, Zadeh M, Owen JL, Colliou N, Li E, Johannssen T, Lepenies B, Klaenhammer TR, Mohamadzadeh M. SIGNR3-dependent immune regulation by Lactobacillus acidophilus surface layer protein A in colitis. EMBO J. 2015; 34: 881-95. https://doi.org/10.15252/embj.201490296. [PubMed]

43. Johnson B, Selle K, O'Flaherty S, Goh YJ, Klaenhammer T. Identification of extracellular surface-layer associated proteins in Lactobacillus acidophilus NCFM. Microbiology. 2013; 159: 2269-82. https://doi.org/10.1099/mic.0.070755-0. [PubMed]

44. Johnson BR, O'Flaherty S, Goh YJ, Carroll I, Barrangou R, Klaenhammer TR. The S-layer Associated Serine Protease Homolog PrtX Impacts Cell Surface-Mediated MicrobeHost Interactions of Lactobacillus acidophilus NCFM. Front Microbiol. 2017; 8: 1185. https://doi.org/10.3389/ fmicb.2017.01185. [PubMed]

45. Rong J, Zheng H, Liu M, Hu X, Wang T, Zhang X, Jin F, Wang L. Probiotic and anti-inflammatory attributes of an isolate Lactobacillus helveticus NS8 from Mongolian fermented koumiss. BMC Microbiol. 2015; 15: 196. https:// doi.org/10.1186/s12866-015-0525-2. [PubMed] 
46. Uroić K, Novak J, Hynönen U, Pietilä TE, Leboš Pavunc A, Kant R, Kos B, Palva A, Šušković J. The role of S-layer in adhesive and immunomodulating properties of probiotic starter culture Lactobacillus brevis D6 isolated from artisanal smoked fresh cheese. Lebenson Wiss Technol. 2016; 69: 623-32. https://doi.org/10.1016/j. lwt.2016.02.013.

47. Mukherjee S, Karmakar S, Babu SP. TLR2 and TLR4 mediated host immune responses in major infectious diseases: a review. Braz J Infect Dis. 2016; 20: 193-204. https://doi.org/10.1016/j.bjid.2015.10.011. [PubMed]

48. Mogensen TH. Pathogen recognition and inflammatory signaling in innate immune defenses. Clin Microbiol Rev. 2009; 22: 240-73. https://doi.org/10.1128/CMR.00046-08. [PubMed]

49. Paolillo R, Romano Carratelli C, Sorrentino S, Mazzola N, Rizzo A. Immunomodulatory effects of Lactobacillus plantarum on human colon cancer cells. Int Immunopharmacol. 2009; 9: 1265-71. https://doi. org/10.1016/j.intimp.2009.07.008. [PubMed]

50. Lu YC, Yeh WC, Ohashi PS. LPS/TLR4 signal transduction pathway. Cytokine. 2008; 42: 145-51. https://doi. org/10.1016/j.cyto.2008.01.006. [PubMed]

51. Vizoso Pinto MG, Rodriguez Gómez M, Seifert S, Watzl B, Holzapfel WH, Franz CM. Lactobacilli stimulate the innate immune response and modulate the TLR expression of HT29 intestinal epithelial cells in vitro. Int J Food Microbiol. 2009; 133: 86-93. https://doi.org/10.1016/j. ijfoodmicro.2009.05.013. [PubMed]

52. Cammarota M, De Rosa M, Stellavato A, Lamberti M, Marzaioli I, Giuliano M. In vitro evaluation of Lactobacillus plantarum DSMZ 12028 as a probiotic: emphasis on innate immunity. Int J Food Microbiol. 2009; 135: 90-98. https:// doi.org/10.1016/j.ijfoodmicro.2009.08.022. [PubMed]

53. Gao K, Wang C, Liu L, Dou X, Liu J, Yuan L, Zhang W, Wang $\mathrm{H}$. Immunomodulation and signaling mechanism of Lactobacillus rhamnosus GG and its components on porcine intestinal epithelial cells stimulated by lipopolysaccharide. J Microbiol Immunol Infect. 2017; 50: 700-13. https://doi. org/10.1016/j.jmii.2015.05.002. [PubMed]

54. Bowen JM, Stringer AM, Gibson RJ, Yeoh AS, Hannam S, Keefe DM. VSL\#3 probiotic treatment reduces chemotherapy-induced diarrhea and weight loss. Cancer Biol Ther. 2007; 6: 1449-54. https://doi.org/10.4161/ cbt.6.9.4622. [PubMed]

55. Kato S, Hamouda N, Kano Y, Oikawa Y, Tanaka Y, Matsumoto K, Amagase K, Shimakawa M. Probiotic Bifidobacterium bifidum G9-1 attenuates 5-fluorouracilinduced intestinal mucositis in mice via suppression of dysbiosis-related secondary inflammatory responses. Clin Exp Pharmacol Physiol. 2017; 44: 1017-25. https://doi. org/10.1111/1440-1681.12792. [PubMed]

56. Trindade LM, Martins VD, Rodrigues NM, Souza EL, Martins FS, Costa GM, Almeida-Leite CM, Faria AM,
Cardoso VN, Maioli TU, Generoso SV. Oral administration of Simbioflora ${ }^{\circledR}$ (synbiotic) attenuates intestinal damage in a mouse model of 5-fluorouracil-induced mucositis. Benef Microbes. 2018; 9: 477-86. https://doi.org/10.3920/ BM2017.0082. [PubMed]

57. Carvalho RD, Breyner N, Menezes-Garcia Z, Rodrigues NM, Lemos L, Maioli TU, da Gloria Souza D, Carmona D, de Faria AM, Langella P, Chatel JM, Bermúdez-Humarán LG, Figueiredo HC, et al. Secretion of biologically active pancreatitis-associated protein I (PAP) by genetically modified dairy Lactococcus lactis NZ9000 in the prevention of intestinal mucositis. Microb Cell Fact. 2017; 16: 27. https://doi.org/10.1186/s12934-017-0624-x. [PubMed]

58. Lycke NY, Bemark M. The regulation of gut mucosal IgA B-cell responses: recent developments. Mucosal Immunol. 2017; 10: 1361-74. https://doi.org/10.1038/mi.2017.62. [PubMed]

59. Schmucker DL, Owen RL, Outenreath R, Thoreux K. Basis for the age-related decline in intestinal mucosal immunity. Clin Dev Immunol. 2003; 10: 167-72. https://doi.org/10.1 080/10446670310001642168. [PubMed]

60. Sakaguchi S, Wing K, Onishi Y, Prieto-Martin P, Yamaguchi T. Regulatory $\mathrm{T}$ cells: how do they suppress immune responses? Int Immunol. 2009; 21: 1105-11. https://doi. org/10.1093/intimm/dxp095. [PubMed]

61. Fontenot JD, Gavin MA, Rudensky AY. Foxp3 programs the development and function of CD4+CD25+ regulatory T cells. Nat Immunol. 2003; 4: 330-36. https://doi. org/10.1038/ni904. [PubMed]

62. Wei Y, Lu C, Chen J, Cui G, Wang L, Yu T, Yang Y, Wu W, Ding Y, Li L, Uede T, Chen Z, Diao H. High salt diet stimulates gut Th17 response and exacerbates TNBSinduced colitis in mice. Oncotarget. 2017; 8: 70-82. https:// doi.org/10.18632/oncotarget.13783. [PubMed]

63. Monteleone I, Marafini I, Dinallo V, Di Fusco D, Troncone E, Zorzi F, Laudisi F, Monteleone G. Sodium chlorideenriched Diet Enhanced Inflammatory Cytokine Production and Exacerbated Experimental Colitis in Mice. J Crohns Colitis. 2017; 11: 237-45. https://doi.org/10.1093/ecco-jcc/ jjw139. [PubMed]

64. Powell N, Walker MM, Talley NJ. The mucosal immune system: master regulator of bidirectional gut-brain communications. Nat Rev Gastroenterol Hepatol. 2017; 14: 143-59. https://doi.org/10.1038/nrgastro.2016.191. [PubMed]

65. Voo KS, Wang YH, Santori FR, Boggiano C, Wang YH, Arima K, Bover L, Hanabuchi S, Khalili J, Marinova E, Zheng B, Littman DR, Liu YJ. Identification of IL-17producing FOXP3+ regulatory T cells in humans. Proc Natl Acad Sci U S A. 2009; 106: 4793-98. https://doi. org/10.1073/pnas.0900408106. [PubMed]

66. Jung MK, Kwak JE, Shin EC. IL-17A-Producing Foxp3+ Regulatory T Cells and Human Diseases. Immune Netw. 
2017; 17: 276-86. https://doi.org/10.4110/in.2017.17.5.276. [PubMed]

67. de Barros PA, Rabelo Andrade ME, de Vasconcelos Generoso S, Mendes Miranda SE, Dos Reis DC, Lacerda Leocádio PC, de Sales E, Souza ÉL, Dos Santos Martins F, da Gama MA, Cassali GD, Alvarez Leite JI, Antunes Fernandes SO, Cardoso VN. Conjugated linoleic acid prevents damage caused by intestinal mucositis induced by 5-fluorouracil in an experimental model. Biomed Pharmacother. 2018; 103: 1567-76. https://doi. org/10.1016/j.biopha.2018.04.133. [PubMed]

68. Galdino FMP, Andrade MER, de Barros PAV, Generoso SV, Alvarez-Leite JI, de Almeida-Leite CM. Peluzio MDCG, Fernandes SOA, Cardoso VN. Pretreatment and treatment with fructo-oligosaccharides attenuate intestinal mucositis induced by 5-FU in mice. J Funct Foods. 2018; 49: 485-92. https://doi.org/10.1016/i.jff.2018.09.012

69. Wardill HR, Gibson RJ, Logan RM, Bowen JM. TLR4/ PKC-mediated tight junction modulation: a clinical marker of chemotherapy-induced gut toxicity? Int J Cancer. 2014; 135: 2483-92. https://doi.org/10.1002/ijc.28656. [PubMed]

70. Corridoni D, Pastorelli L, Mattioli B, Locovei S, Ishikawa D, Arseneau KO, Chieppa M, Cominelli F, Pizarro TT. Probiotic bacteria regulate intestinal epithelial permeability in experimental ileitis by a TNF-dependent mechanism. PLoS One. 2012; 7: e42067. https://doi.org/10.1371/journal. pone.0042067. [PubMed]

71. Mennigen R, Nolte K, Rijcken E, Utech M, Loeffler B, Senninger N, Bruewer M. Probiotic mixture VSL\#3 protects the epithelial barrier by maintaining tight junction protein expression and preventing apoptosis in a murine model of colitis. Am J Physiol Gastrointest Liver Physiol. 2009; 296: G1140-49. https://doi.org/10.1152/ajpgi.90534.2008. [PubMed]

72. Henderson P, van Limbergen JE, Schwarze J, Wilson DC. Function of the intestinal epithelium and its dysregulation in inflammatory bowel disease. Inflamm Bowel Dis. 2011; 17: 382-95. https://doi.org/10.1002/ibd.21379. [PubMed]

73. Mi H, Dong Y, Zhang B, Wang H, Peter CC, Gao P, $\mathrm{Fu} \mathrm{H}$, Gao Y. Bifidobacterium Infantis Ameliorates Chemotherapy-Induced Intestinal Mucositis Via Regulating T Cell Immunity in Colorectal Cancer Rats. Cell Physiol Biochem. 2017; 42: 2330-41. https://doi. org/10.1159/000480005. [PubMed]

74. Justino PF, Melo LF, Nogueira AF, Morais CM, Mendes WO, Franco AX, Souza EP, Ribeiro RA, Souza MH, Soares PM. Regulatory role of Lactobacillus acidophilus on inflammation and gastric dysmotility in intestinal mucositis induced by 5 -fluorouracil in mice. Cancer Chemother Pharmacol. 2015; 75: 559-67. https://doi.org/10.1007/ s00280-014-2663-x. [PubMed]

75. Foligne B, Nutten S, Grangette C, Dennin V, Goudercourt D, Poiret S, Dewulf J, Brassart D, Mercenier A, Pot B. Correlation between in vitro and in vivo immunomodulatory properties of lactic acid bacteria. World J Gastroenterol. 2007; 13: 236-43. [PubMed]

76. Suschek CV, Schnorr O, Kolb-Bachofen V. The role of iNOS in chronic inflammatory processes in vivo: is it damagepromoting, protective, or active at all? Curr Mol Med. 2004; 4: 763-75. https://doi.org/10.2174/1566524043359908. [PubMed]

77. Miljkovic D, Trajkovic V. Inducible nitric oxide synthase activation by interleukin-17. Cytokine Growth Factor Rev. 2004; 15: 21-32. https://doi.org/10.1016/j. cytogfr.2003.10.003. [PubMed]

78. Niess JH, Leithäuser F, Adler G, Reimann J. Commensal gut flora drives the expansion of proinflammatory CD4 $\mathrm{T}$ cells in the colonic lamina propria under normal and inflammatory conditions. J Immunol. 2008; 180: 559-68. https://doi.org/10.4049/jimmunol.180.1.559. [PubMed]

79. Malik AC, Reinbold GW, Vedamuthu ER. An evaluation of the taxonomy of Propionibacterium. Can J Microbiol. 1968; 14: 1185-91. https://doi.org/10.1139/m68-199. [PubMed]

80. MacPherson BR, Pfeiffer CJ. Experimental production of diffuse colitis in rats. Digestion. 1978; 17: 135-50. https:// doi.org/10.1159/000198104. [PubMed]

81. Santos Rocha C, Gomes-Santos AC, Garcias Moreira T, de Azevedo M, Diniz Luerce T, Mariadassou M, Longaray Delamare AP, Langella P, Maguin E, Azevedo V, Caetano de Faria AM, Miyoshi A, van de Guchte M. Local and systemic immune mechanisms underlying the anti-colitis effects of the dairy bacterium Lactobacillus delbrueckii. PLoS One. 2014; 9: e85923. https://doi.org/10.1371/journal. pone.0085923. [PubMed]

82. Rezende RM, Oliveira RP, Medeiros SR, Gomes-Santos AC, Alves AC, Loli FG, Guimarães MA, Amaral SS, da Cunha AP, Weiner HL, Azevedo V, Miyoshi A, Faria AM. Hsp65-producing Lactococcus lactis prevents experimental autoimmune encephalomyelitis in mice by inducing CD4+LAP+ regulatory $\mathrm{T}$ cells. J Autoimmun. 2013; 40: 45-57. https://doi.org/10.1016/j.jaut.2012.07.012. [PubMed]

83. Canesso MC, Lemos L, Neves TC, Marim FM, Castro TB, Veloso ÉS, Queiroz CP, Ahn J, Santiago HC, Martins FS, Alves-Silva J, Ferreira E, Cara DC, et al. The cytosolic sensor STING is required for intestinal homeostasis and control of inflammation. Mucosal Immunol. 2018; 11: 820 34. https://doi.org/10.1038/mi.2017.88. [PubMed]

84. Oliveira JS, Costa K, Acurcio LB, Sandes SH, Cassali GD, Uetanabaro AP, Costa AM, Nicoli JR, Neumann E, Porto AL. In vitro and in vivo evaluation of two potential probiotic lactobacilli isolated from cocoa fermentation (Theobroma cacao L.). J Funct Foods. 2018; 47: 184-91. https://doi.org/10.1016/j.jff.2018.05.055

85. Giulietti A, Overbergh L, Valckx D, Decallonne B, Bouillon $\mathrm{R}$, Mathieu C. An overview of real-time quantitative PCR: applications to quantify cytokine gene expression. Methods. 2001; 25: 386-401. https://doi.org/10.1006/ meth.2001.1261. [PubMed] 
86. Hu GQ, Song PX, Li N, Chen W, Lei QQ, Yu SX, Zhang XJ, Du CT, Deng XM, Han WY, Yang YJ. AIM2 contributes to the maintenance of intestinal integrity via Akt and protects against Salmonella mucosal infection. Mucosal Immunol. 2016; 9: 1330-39. https://doi.org/10.1038/mi.2015.142. [PubMed]

87. Tokumasu R, Yamaga K, Yamazaki Y, Murota H, Suzuki K, Tamura A, Bando K, Furuta Y, Katayama I, Tsukita S. Dosedependent role of claudin-1 in vivo in orchestrating features of atopic dermatitis. Proc Natl Acad Sci U S A. 2016; 113: E4061-68. https://doi.org/10.1073/pnas.1525474113. [PubMed]

88. Wlodarska M, Willing B, Keeney KM, Menendez A, Bergstrom KS, Gill N, Russell SL, Vallance BA, Finlay $\mathrm{BB}$. Antibiotic treatment alters the colonic mucus layer and predisposes the host to exacerbated Citrobacter rodentiuminduced colitis. Infect Immun. 2011; 79: 1536-45. https:// doi.org/10.1128/IAI.01104-10. [PubMed]

89. Hellemans J, Mortier G, De Paepe A, Speleman F, Vandesompele J. qBase relative quantification framework and software for management and automated analysis of real-time quantitative PCR data. Genome Biol. 2007; 8: R19. https://doi.org/10.1186/gb-2007-8-2-r19. [PubMed]

90. Carrasco-Pozo C, Morales P, Gotteland M. Polyphenols protect the epithelial barrier function of Caco-2 cells exposed to indomethacin through the modulation of occludin and zonula occludens-1 expression. J Agric Food Chem. 2013; 61: 5291-97. https://doi.org/10.1021/ if400150p. [PubMed] 